Numerical and experimental investigation of dielectric recovery in supercritical $\mathrm{N}_{2}$

This content has been downloaded from IOPscience. Please scroll down to see the full text.

2015 Plasma Sources Sci. Technol. 24025008

(http://iopscience.iop.org/0963-0252/24/2/025008)

View the table of contents for this issue, or go to the journal homepage for more

Download details:

IP Address: 131.155.2.68

This content was downloaded on 10/02/2015 at 18:24

Please note that terms and conditions apply. 


\title{
Numerical and experimental investigation of dielectric recovery in supercritical $\mathrm{N}_{2}$
}

\author{
J Zhang $^{1}$, A H Markosyan ${ }^{2,3}$, M Seeger ${ }^{4}$, E M van Veldhuizen ${ }^{5}$, \\ E J M van Heesch ${ }^{1}$ and U Ebert ${ }^{2,5}$ \\ ${ }^{1}$ Department of Electrical Engineering, Eindhoven University of Technology, PO Box 513, 5600 MB, \\ Eindhoven, The Netherlands \\ ${ }^{2}$ Centrum voor Wiskunde en Informatica (CWI), PO Box 94079, 1090 GB Amsterdam, The Netherlands \\ ${ }^{3}$ Electrical Engineering and Computer Science Department, University of Michigan, Ann Arbor, MI \\ 48109, USA \\ ${ }^{4}$ ABB Switzerland Ltd, Corporate Research, Segelhofstrasse 1, CH-5405 Baden-Dättwil, Switzerland \\ ${ }^{5}$ Department of Applied Physics, Eindhoven University of Technology, PO Box 513, 5600 MB \\ Eindhoven, The Netherlands \\ E-mail: jin.zhang@tue.nl and armarkos@umich.edu
}

Received 12 May 2014, revised 17 December 2014

Accepted for publication 5 January 2015

Published 5 February 2015

\begin{abstract}
A supercritical (SC) nitrogen $\left(\mathrm{N}_{2}\right)$ switch is designed and tested. The dielectric strength and recovery rate of the SC switch are investigated by experiments. In order to theoretically study the discharge and recovery process of the $\mathrm{SC} \mathrm{N}_{2}$ switch under high repetition rate operation, a numerical model is developed. For SC $\mathrm{N}_{2}$ with initial parameters of $\mathrm{p}=80.9$ bar and $T=300 \mathrm{~K}$, the simulation results show that within several nanoseconds after the streamer bridges the switch gap, the spark is fully developed and this time depends on the applied electric field between electrodes. During the whole discharge process, the maximum temperature in the channel is about $20000 \mathrm{~K}$. About $10 \mu \mathrm{s}$ after the spark excitation of $200 \mathrm{~ns}$ duration, the temperature on the axis decays to $T_{\text {axis }} \leqslant 1500 \mathrm{~K}$, mainly contributed by the gas expansion and heat transfer mechanisms. After $100 \mu \mathrm{s}$, the dielectric strength of the gap recovers to above half of the cold breakdown voltage due to the temperature decay in the channel. Both experimental and numerical investigations indicate that supercritical fluid is a good insulating medium that has a proved high breakdown voltage and fast recovery speed.
\end{abstract}

Keywords: supercritical fluid, numerical simulation, dielectric strength, dielectric recovery, pulsed power switch

(Some figures may appear in colour only in the online journal)

\section{Introduction}

Electric switches in power system networks, typically circuit breakers (CBs), are responsible for the protection of the power system components and the control of the power flow. When switching normal load current or when detecting an overload or short-circuit fault, CBs must interrupt the current quickly, and regain the dielectric strength rapidly after the interruption, especially in high voltage circuit breakers (HVCBs). In other words, a high dielectric strength and a fast dielectric recovery speed are the two vital characteristics of such electric switches. $\mathrm{SF}_{6}$ as a switching medium dominates in the HVCBs, because of its excellent interrupting capability $[1,2]$. However, $\mathrm{SF}_{6}$ has disadvantages: it is a strong greenhouse gas, and its degradation products are toxic. It is important to find a switching medium with excellent interrupting performance but which is environmentally harmless, as an alternative to $\mathrm{SF}_{6}$. Several investigations have been undertaken to study other insulating media in $\mathrm{CBs}$ aiming on replacement of $\mathrm{SF}_{6}$ [3-7]. However, no promising alternative to $\mathrm{SF}_{6}$ has been found.

Supercritical fluids ( $\mathrm{SCF}$ ), widely researched in the field of chemistry $[8,9]$, have recently drawn scientists' attention to their potential in the area of electrical switching. The reason is that a SCF combines the advantages of liquids and 


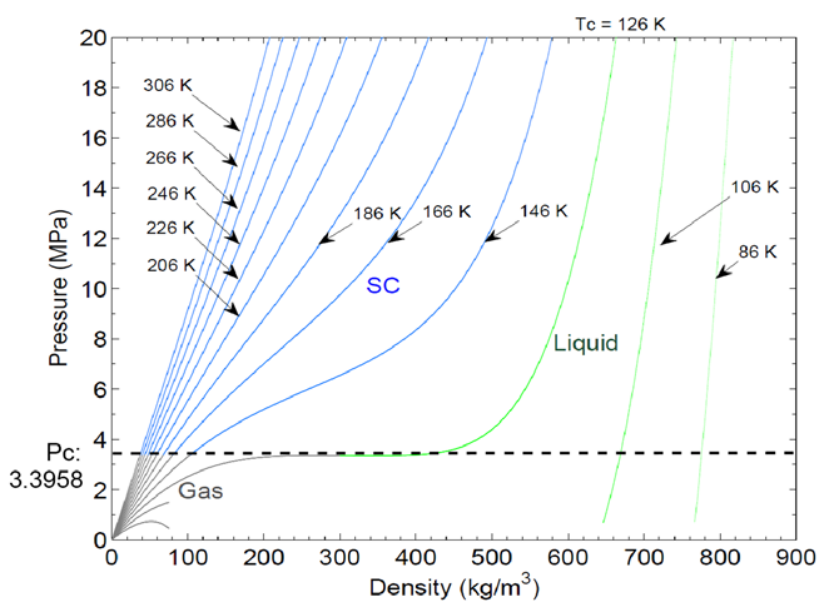

Figure 1. Phase diagram of $\mathrm{N}_{2}$ covering pressure up to $20 \mathrm{MPa}$, temperature in the range $86-306 \mathrm{~K}[12] . P_{\mathrm{c}}=3.3958 \mathrm{MPa}$ and $T_{\mathrm{c}}=126 \mathrm{~K}$ represent the critical pressure and temperature of $\mathrm{N}_{2}$, respectively.

gases: high density and high heat conductivity (corresponding to high dielectric strength); large mass transfer capability due to low viscosity and high diffusion (corresponding to the fast dielectric recovery capability) $[10,11]$. Existing data about the breakdown voltage inside SCF have proven a satisfying dielectric strength of SCF [12,13-16], but the dielectric recovery process after the breakdown in SCF remains unexplored. The discharge and recovery process of a gas after breakdown can be analyzed theoretically using mathematical modeling. Recent modeling works focus on different discharge stages: the streamer stage, which is from the avalanche generation to streamer propagation $[17,18]$; the streamer-tospark transition stage, that is after the streamer crosses the gap, until the spark formation [19-27]; and the discharge \& postdischarge stage, that is the time after the spark formation, until dielectric recovery of the switch gap [28-31]. However, none of them combines all these stages and simulates the complete discharge process, and the discharge process in SCF has not been explored at all.

The goal of this work is to experimentally (by a repetitive voltage source) and theoretically (by a numerical model) study the breakdown and recovery process inside a SCF. SC $\mathrm{N}_{2}$ is chosen to be the studied medium in this work, because of its relatively low critical pressure of $P_{\mathrm{c}}=3.396 \mathrm{MPa}$ and low critical temperature of $T_{\mathrm{c}}=126 \mathrm{~K}$. Experiments with $\mathrm{SC} \mathrm{N}_{2}$ can be performed at room temperature. $\mathrm{N}_{2}$ is the major component of the Earth's atmosphere, so it has no environmental impact. Figure 1 gives the phase diagram of $\mathrm{N}_{2}$ in gas, liquid and SC state [12].

In section 2 the experimental setup of a SC switch is introduced, and basic measurements for the inputs of the model are given. The breakdown voltage and the recovery percentage of a SC $\mathrm{N}_{2}$ switch are measured experimentally. In section 3 we present a mathematical model to study the discharge and recovery process of a SCF. The results of the experiments and the model are discussed in section 4 . In section 5 the conclusions are given.

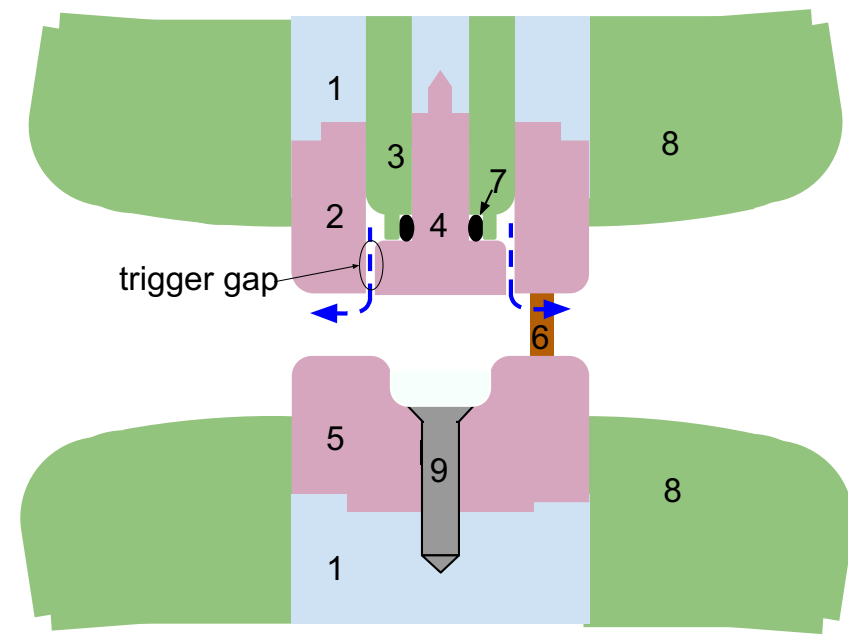

Figure 2. Schematic cross section of our SC switch. The SC switch is cylindrically symmetric. $\mathrm{SC} \mathrm{N}_{2}$ flows through the path indicated by dashed line arrows: 1 - stainless steel electrode body; 2 -tungsten copper (WCu 75/25) anode; 3-quartz filled epoxy insulator; 4- WCu 75/25 trigger electrode; 5-WCu 75/25 cathode; 6-typical region of spark channel when switch breaks down; 7-O-ring for SCFs sealing; 8-insulator body; 9-metal screw to fix the cathode to the electrode body.

\section{Experiment of $\mathrm{SC} \mathrm{N}_{2}$ switch}

We have designed and tested a SC plasma switch for pulsed operation in repetitive mode (200 ns pulse duration and 10 $1000 \mathrm{~Hz}$ pulses per second). During the experiment the pressure of the SCF covers 32-95 bar and the adjustable gap width varies from $0.2-0.45 \mathrm{~mm}$ with an estimated accuracy of $\pm 0.01 \mathrm{~mm}$. In our experiment we keep $\mathrm{N}_{2}$ at room temperature. Figure 2 sketches the electrodes and SCF gap of the SC switch. The anode (2) has an annular configuration with an inner diameter of $10 \mathrm{~mm}$ and an outer diameter of $24 \mathrm{~mm} . \mathrm{N}_{2}$ flows through the gap between the trigger pin (4) and the anode (2), and then through the gap between the anode and the cathode (5). The cathode is a planar electrode with the same diameter as the anode.

The electric circuit applied to the SC switch is given in figure 3. It supplies pulse voltages with the repetition frequency $10-1000 \mathrm{~Hz}$. An LCR circuit [32] is used to trigger the breakdown of the SC switch. The spark channel develops randomly in the gap, e.g. position (6) between the two electrodes. The current is measured by a Rogowski coil with the bandwidth up to $15 \mathrm{MHz}$ mounted on the cathode, and the breakdown voltage is measured by a high voltage probe with the bandwidth up to $90 \mathrm{MHz}$ on the anode. Figure 4 gives an example of the voltage measured on the anode of the SC switch, with pressure $80 \mathrm{bar}$ and gap distance $0.3 \mathrm{~mm}$. One 4stage transmission line transformer (TLT) amplifies the output voltage of the switch by a factor of four, providing the chance for further investigation of SCF under pulsed voltage with the peak value $120 \mathrm{kV}$. For this work, one $200 \Omega$ matching load is connected to the output of the TLT.

Normally the breakdown voltage of a gas increases with the product of pressure and gap width $p d$ [33-35], except the local minimum value around the critical points in micro gaps 


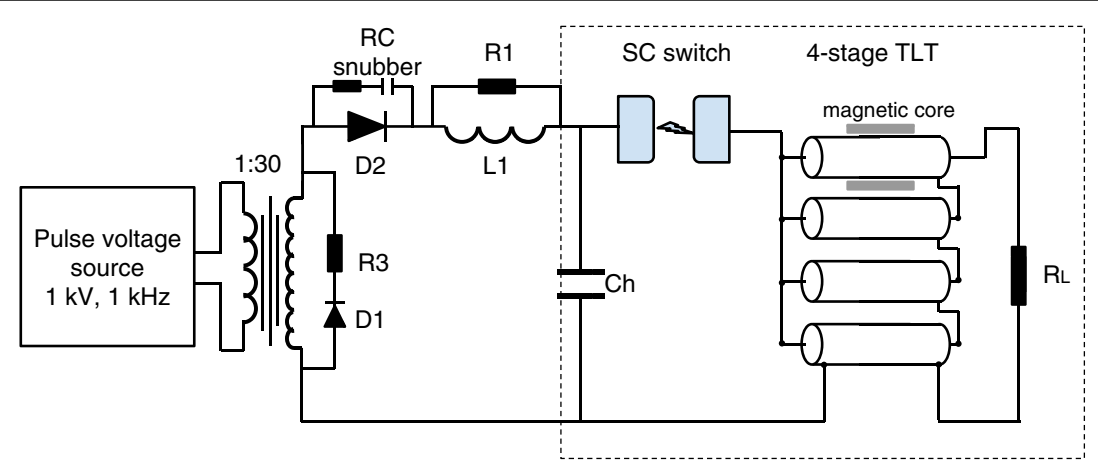

Figure 3. Schematic of charging circuit for the SC switch. $C_{\mathrm{h}}$ - high-voltage capacitor; $\mathrm{L}_{1}$-inductance for the resonant charging circuit for $C_{\mathrm{h}}$; TLT-transmission line transformer; $R_{\mathrm{L}}$-resistive load to match the impedance of the TLT.

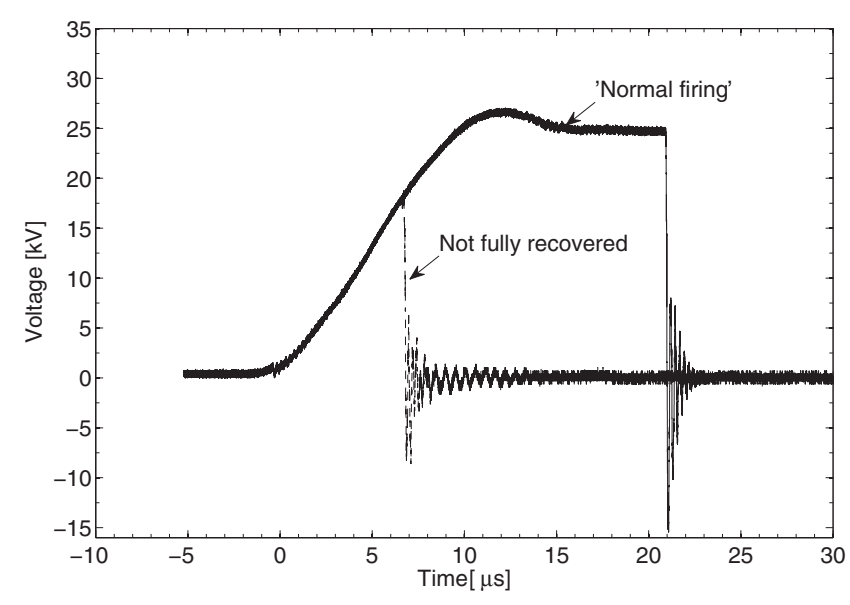

Figure 4. Example of voltage waveform measured on the anode of the $\mathrm{SC} \mathrm{N}_{2}$ switch under breakdown of fully recovered and not fully recovered.

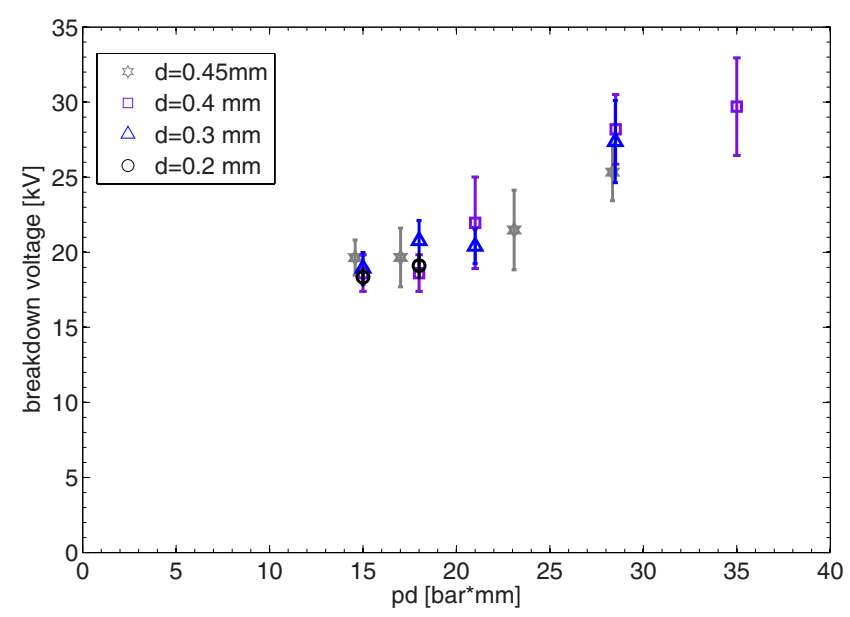

Figure 5. Measured breakdown voltage of the $\mathrm{SC} \mathrm{N}_{2}$ switch as a function of $p d$ under $1 \mathrm{kHz}, 30 \mathrm{kV}$ peak voltage repetitive source.

$[36,37]$. In $\mathrm{SC} \mathrm{N}_{2}$, the same behavior is observed. Figure 5 gives the measured breakdown voltage $U_{\mathrm{bd}}$ as a function of $p d$ under the repetitive source with a time lag between two succeeding pulses set to $1 \mathrm{~ms}$. The error bar in the figure represents the scattering of measured breakdown voltages for 40 shots per data point. The breakdown strength of the $\mathrm{SC} \mathrm{N}_{2}$ increases with higher $p d$.

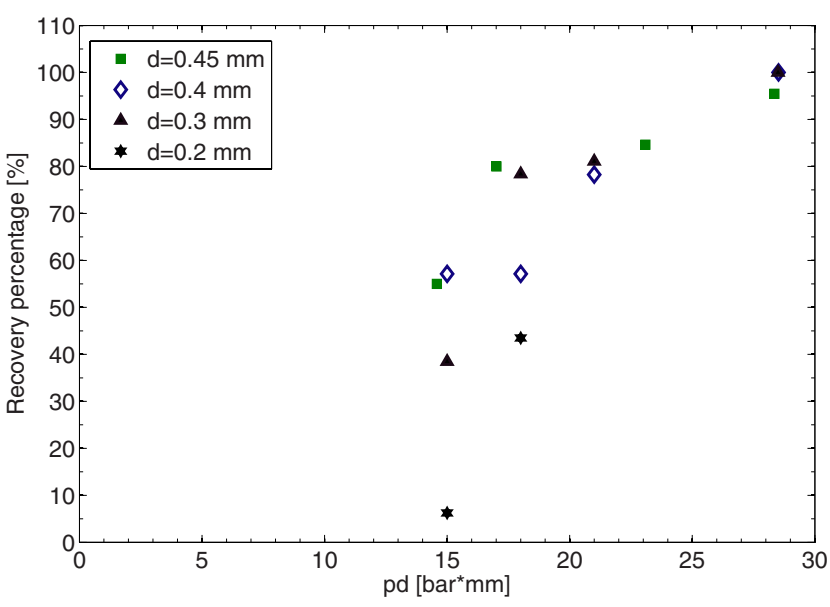

Figure 6. The recovery percentage of $\mathrm{SC}_{2}$ switch estimated from experiment, under $1 \mathrm{kHz}, 30 \mathrm{kV}$ peak voltage repetitive source.

Due to the LC resonant charging circuit, the rise time $t_{\mathrm{r}}$ of the voltage from 0 to its peak value of $30 \mathrm{kV}$ is almost constant. Under repetitive operation, if the dielectric strength of the switch recovers completely from the previous breakdown, the switch breaks down shortly after the voltage rises to the peak value, which is called a 'normal firing'. On the other hand, if the SC switch does not recover completely, the gap will break down before the voltage reaches the peak value. The percentage of shots undergoing 'normal firing' to the total number of shots is defined as the recovery percentage of the SC switch. Figure 6 shows the recovery percentage of the SC $\mathrm{N}_{2}$ estimated from our definition, as a function of $p d$ under $1 \mathrm{kHz}$ repetitive source. For $p d<15$ bar mm the percentage of normal firing will become too low, so we perform the experiment only above this value. From the figure we can see that the recovery percentage of the SC switch is larger than $80 \%$ within $1 \mathrm{~ms}$, if the value of $p d \geqslant 18 \mathrm{bar} \mathrm{mm}$, and $d>0.2 \mathrm{~mm}$.

For the numerical modeling described later in section 3, the electric field $E$ is one of the input parameters. From the measured current, we can calculate the time evolution of the electric field using the discharging circuit diagram of the SC switch given in figure 7 [38]. The electric field can be 


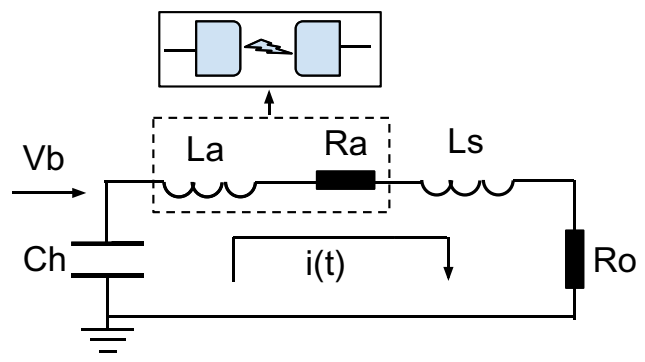

Figure 7. Simplified circuit of the dotted box in figure 3 . $i(t)$-measured current in the circuit; $V_{\mathrm{b}}$-measured breakdown voltage; $L_{\mathrm{a}}$ - arc inductance; $R_{\mathrm{a}}$ - arc resistance; $C_{\mathrm{h}}$ - high voltage capacitance; $L_{\mathrm{s}}$ - stray inductance in the circuit; $R_{0}$-total resistance in the circuit (including stray resistance and load resistance).

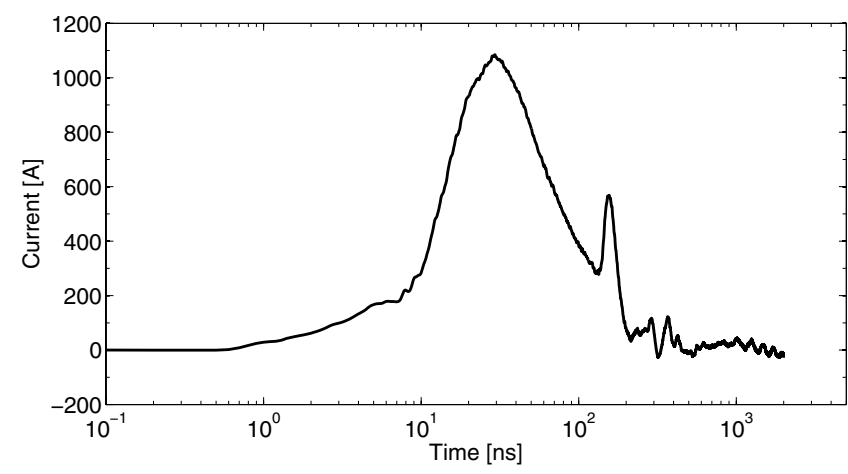

Figure 8. A typical arc current in our experimental SC switch with applied voltage $25 \mathrm{kV}$ and gap width $0.3 \mathrm{~mm}$. The pressure of SC $\mathrm{N}_{2}$ is 80 bar under the room temperature.

calculated with the following formulas:

$$
\begin{aligned}
R_{\mathrm{a}}(t)= & \frac{1}{i(t)}\left\{V_{\mathrm{b}}-\frac{1}{C_{\mathrm{h}}} \int_{0}^{t} i(\tau) \mathrm{d} \tau-\left[L_{\mathrm{s}}+L_{\mathrm{a}}(t)\right] \frac{\mathrm{d} i(t)}{\mathrm{d} t}\right. \\
& \left.-\left[R_{0}+\frac{\mathrm{d} L_{\mathrm{a}}(t)}{\mathrm{d} t}\right] i(t)\right\}, \\
E(t)= & \frac{1}{d}\left[i(t) \cdot R_{\mathrm{a}}(t)+L_{\mathrm{a}}(t) \frac{\mathrm{d} i(t)}{\mathrm{d} t}\right],
\end{aligned}
$$

where $i(t)$ is the measured current, with a typical profile given in figure 8 (the second peak of the $i(t)$ curve at a time of about $150 \mathrm{~ns}$ is due to a reflection from the not well matched TLT mounted behind the SC switch); $V_{\mathrm{b}}$ is the breakdown voltage measured on the anode; $L_{\mathrm{s}}=104 \mathrm{nH}$ is the stray inductance in the circuit; $R_{0}=12.6 \Omega$ is the resistance in the circuit, including the stray resistance and the input resistance of the TLT (12.5 $\Omega) ; d$ is the gap width; $L_{\mathrm{a}}(t)$ is the inductance of the spark channel calculated by assuming a spark channel radius of $r_{\mathrm{s}}=35 \mu \mathrm{m}$. The value of $r_{\mathrm{s}}$ is estimated by imaging with an ICCD camera, as will be described in the next paragraph. $L_{\mathrm{a}}(t)$ is found to be much smaller than the value of $L_{\mathrm{s}}$. The calculated electric field $\mathrm{E}$ is shown in figure $9(a)$. The oscillation on the tail of the curve is due to the resonance oscillation between the inductance and capacitance in the circuit. We use the smoothed curve of the calculated $E$ with moving average of $10 \%$ of the total number of data points, shown in figure $9(b)$, as the electric field profile that will be applied to the switch gap in the numerical modeling.
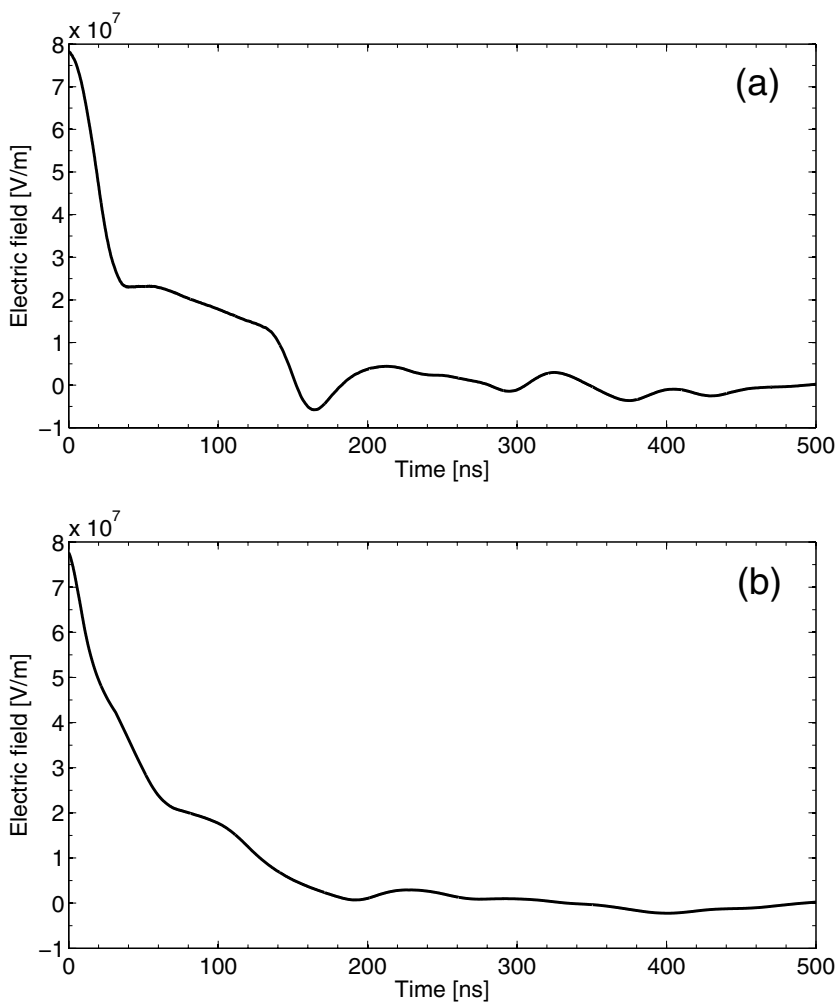

Figure 9. (a) Estimated average electric field $E$ from measured arc current in figure 8, with applied voltage $25 \mathrm{kV}$ and gap width $0.3 \mathrm{~mm}$. (b) Smoothed electric field $E$ of ( $a$ ) with span of $10 \%$, for the input of numerical modeling in section 3 .

Photographs of the discharge in the $\mathrm{SC}_{2}$ are taken with an intensified CCD camera mounted with a microscope lens. The ICCD camera is a 4 Picos from Stanford Computer Optics with $780 \times 580$ pixels, $8.3 \times 8.3 \mu \mathrm{m}$ pixel size. The camera is synchronized with the pulsed voltage supplied to the trigger electrode of the SC switch. We use a delay cable to synchronize the opening of the ICCD camera with the discharge in the $\mathrm{SC}$ switch. In order to prevent the overexposure of the camera, one neutral density (ND) filter (with variable ND 2$400 \times$ ) is placed between the optical window of the SC switch and the microscope lens. Figure 10 gives the image of the discharge channel in $\mathrm{SC}_{2}$ at a pressure of 70 bar taken by the ICCD camera at the moment when the current appears in the gap. With an exposure time of $0.3 \mathrm{~ns}$, the discharge diameter measured as the full-width at half-maximum (FWHM) of the peak intensity is estimated to be $70 \mu \mathrm{m}$. Under high pressure condition the streamer transfers to a spark very quickly. The small gap distance also contributes to the fast transfer of streamer to spark. Estimation of streamer crossing time indicates that this channel in figure 10 is somewhat after the streamer stage. From the discharge images, we observe that the discharge radius tends to grow in a later stage. We observe typically only one spark channel during the breakdown of the SC switch, at varying positions of the electrode ring. 


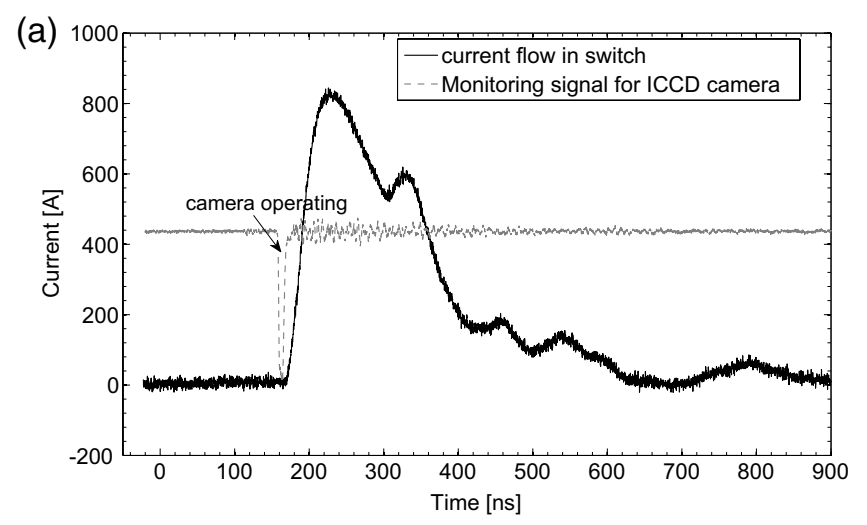

(b)

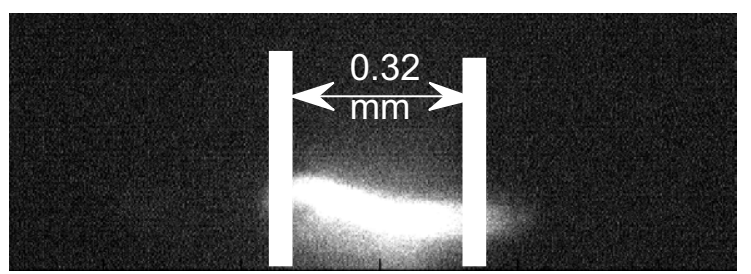

Figure 10. Imaging of breakdown in the $\mathrm{SC} \mathrm{N}_{2}$ switch with an ICCD camera at gap width of $0.32 \mathrm{~mm}$ and pressure of 70 bar. The exposure time of the camera is $0.3 \mathrm{~ns}$; the ND filter intensity is $100 \times$. (b) The discharge channel taken at the moment indicated by the signal shown in $(a)$, and the thick lines in $(b)$ indicate the position of the electrodes.

\section{Model description}

\subsection{General formulation}

If the SC switch undergoes a breakdown process, we assume the discharge occurring in region 6 in figure 2, i.e. in the region of a rather uniform background field. The discharge process is composed of two main phases: streamer-to-spark transition phase and discharge \& post-discharge phase. The two stages of the discharge are briefly introduced here, while the detailed explanation is given in sections 3.2-3.3. In the streamer-to-spark transition phase the streamer forms and propagates, and electric energy from the external source is deposited into the gap. The discharge energy is transferred to different levels: translational motion, rotational levels, vibrational levels, and electronically excited levels as well as dissociation and ionization of $\mathrm{N}_{2}$ molecules. Energy in some excited levels is relaxed to gas heating instantaneously, while the energy in the other excited levels takes time to relax fully. All power density going into gas heating is denoted as $Q_{\text {in }}$. During the relaxation process, there is energy output due to heat conduction and radiation, whose power density is denoted as $Q_{\text {out }}$. The total energy $\varepsilon$ is a result of the energy input, energy output and the gas dynamics. We assume the streamerto-spark transition phase ends when the fluid temperature in the discharge center is larger than $5000 \mathrm{~K}$, then the discharge $\&$ post-discharge phase begins. In this stage the remaining energy in excited levels continues relaxing with a certain time constant; the total energy of the spark channel changes under combined mechanisms; the thermodynamic properties of the $\mathrm{N}_{2}$ in the spark channel recover and finally the dielectric strength of $\mathrm{SC} \mathrm{N}_{2}$ can recover.
The numerical modeling of the discharge process follows the flow chart of the energy transition shown in figure 11. From the detailed streamer simulations [39-41], it is known that in the interior of the streamer channel the electron density can be assumed to be uniform in the axial direction far from the electrodes. Since we do not take into account the effect of the electrodes, we assume a 1D configuration (in the radial direction) to be sufficient for the present work. The Euler equations [19, 42,43] which cover the equations of conservation of mass, momentum and energy are applied in the model. The balance equations of the vibrational energy and electronic excited energy of $\mathrm{N}_{2}$ are included in the following set of equations:

$$
\begin{gathered}
\frac{\partial}{\partial t}\left[\begin{array}{c}
\rho \\
\rho u \\
\varepsilon \\
\varepsilon_{\mathrm{V}} \\
\varepsilon_{\mathrm{E}}
\end{array}\right]+\frac{1}{r} \frac{\partial}{\partial r} r\left[\begin{array}{c}
\rho u \\
\rho u^{2} \\
u(\varepsilon+p) \\
\varepsilon_{\mathrm{V}} u \\
\varepsilon_{\mathrm{E}} u
\end{array}\right]+\frac{\partial}{\partial r}\left[\begin{array}{l}
0 \\
p \\
0 \\
0 \\
0
\end{array}\right] \\
=\left[\begin{array}{c}
0 \\
0 \\
Q_{\mathrm{in}}-Q_{\mathrm{out}} \\
\eta_{\mathrm{V}} Q_{\mathrm{R}}-Q_{\mathrm{VT}} \\
\eta_{\mathrm{E}} Q_{\mathrm{R}}-Q_{\mathrm{ET}}
\end{array}\right],
\end{gathered}
$$

where $\rho\left(\mathrm{kg} \mathrm{m}^{-3}\right)$ is the mass density, $u\left(\mathrm{~m} \mathrm{~s}^{-1}\right)$ the velocity, $p$ (Pa) the pressure, $\varepsilon\left(\mathrm{J} \mathrm{m}^{-3}\right)$ the total energy density, $\varepsilon_{\mathrm{V}}\left(\mathrm{J} \mathrm{m}^{-3}\right)$ the vibrational energy density, $\varepsilon_{\mathrm{E}}\left(\mathrm{J} \mathrm{m}^{-3}\right)$ the electronically excited energy density, $Q_{\text {in }}\left(\mathrm{J} \mathrm{s}^{-1} \mathrm{~m}^{-3}\right)$ the local power input density, $Q_{\text {out }}\left(\mathrm{J} \mathrm{s}^{-1} \mathrm{~m}^{-3}\right)$ the local power output density, $Q_{\mathrm{R}}$ $\left(\mathrm{J} \mathrm{s}^{-1} \mathrm{~m}^{-3}\right)$ the external discharge power input density, $Q_{\mathrm{VT}}$ $\left(\mathrm{J} \mathrm{s}^{-1} \mathrm{~m}^{-3}\right)$ the power density relaxed from vibrational to translational energy level of $\mathrm{N}_{2}$, and $Q_{\mathrm{ET}}\left(\mathrm{J} \mathrm{s}^{-1} \mathrm{~m}^{-3}\right)$ the power density relaxed from electronically excited levels as well as dissociation and ionization of $\mathrm{N}_{2}$ molecules, $\eta_{\mathrm{V}}$ the fraction of the energy which goes into vibrational excited level, $\eta_{\mathrm{E}}$ the energy used for ionization together with the part of electronic excited energy which will not be relaxed immediately. All the units listed in this work are SI unit, unless otherwise specified, and the terms and units in the equations below will not be repeatedly described.

The total energy per unit volume $\varepsilon$ is defined as $\varepsilon=\rho u^{2} / 2+p /(\gamma-1)$, where $\gamma$ is the specific heat ratio depending on gas temperature and pressure [10]. The input power density $Q_{\text {in }}$ is expressed as

$$
Q_{\mathrm{in}}=Q_{\mathrm{T}}+Q_{\mathrm{VT}}+Q_{\mathrm{ET}},
$$

where $Q_{\mathrm{T}}$ is the electric power density going directly into the gas heating; $Q_{\mathrm{VT}}$ and $Q_{\mathrm{ET}}$ have been introduced before. The output power density $Q_{\text {out }}$ is described by

$$
Q_{\text {out }}=Q_{\text {rad }}+Q_{\text {cond }}+Q_{\text {electrode }},
$$

where $Q_{\text {rad }}$ is the output power density due to radiation heat transfer, $Q_{\text {cond }}$ the output due to heat conduction in the radial direction of the spark channel and $Q_{\text {electrode }}$ the output due to heat conduction to the metal electrodes. Energy dissipation due to heat convection is neglected, since the temperature in the outer domain of the spark channel is almost equal to the background temperature. 


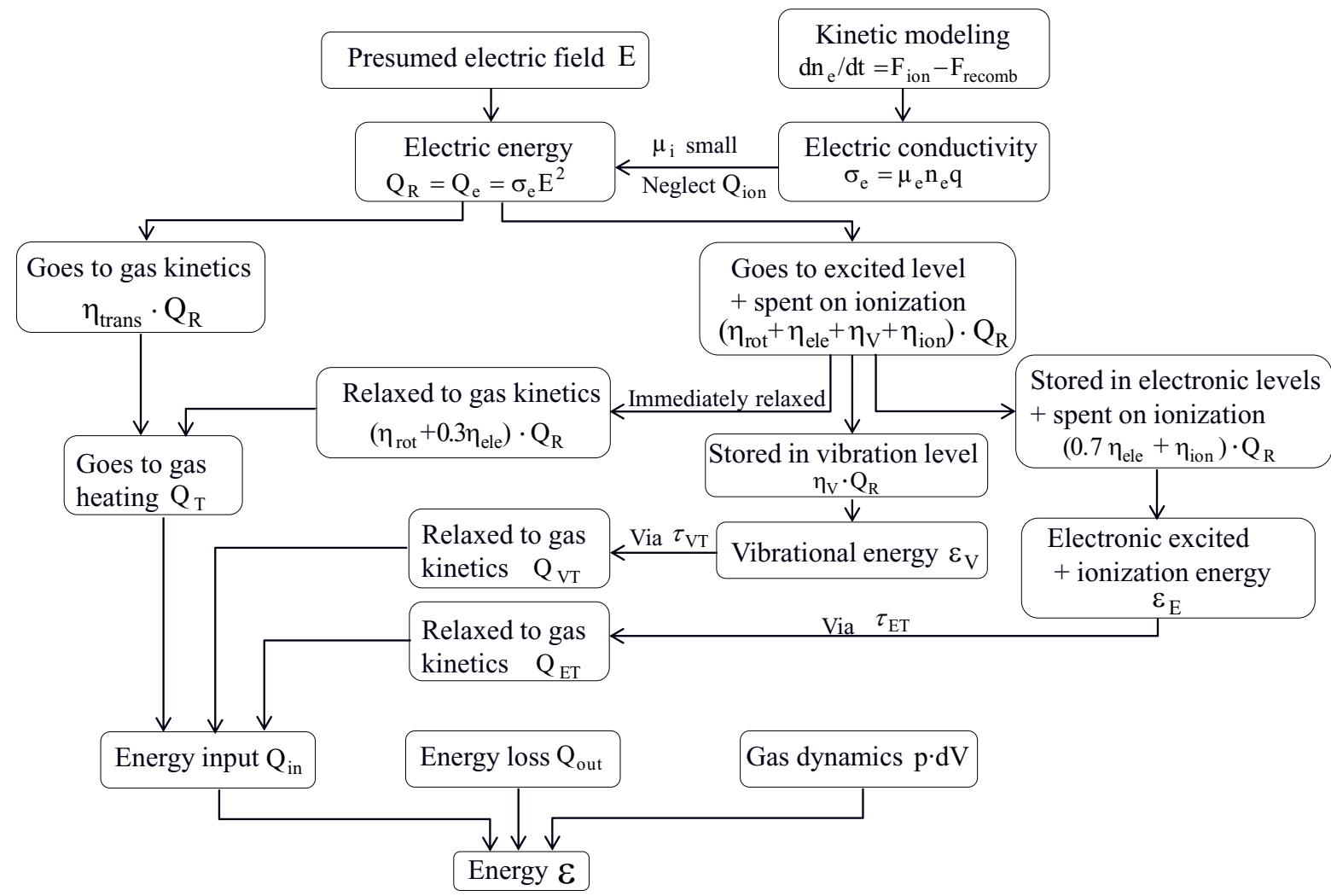

Figure 11. Flow chart of the energy transition in the numerical model of the discharge and recovery process inside a SCF; $E$ : the electric field estimated from equation (2); $n_{\mathrm{e}}$ : the number density of electrons; $F_{\text {ion }}$ and $F_{\text {recomb }}$ : the ionization and recombination coefficients of $\mathrm{N}_{2}$; $Q_{\mathrm{R}}$ : the external discharge power input density; $Q_{\mathrm{e}}$ and $Q_{\text {ion }}$ : the electron and ion component of the discharge power input density; $\sigma_{\mathrm{e}}$ : the electrical conductivity of the electrons; $\mu_{\mathrm{e}}$ : electron mobility; $q_{\mathrm{e}}$ : electron charge; $\eta_{\text {trans }}, \eta_{\text {rot }}, \eta_{\mathrm{V}}, \eta_{\text {ele }}$ and $\eta_{\text {ion }}$ : fractions of energy that go into translational level, rotational level, vibrational level, electronic excited level and ionization of $\mathrm{N}_{2} ; Q_{\mathrm{T}}$ : the electric power density going directly into the gas heating; $Q_{\mathrm{VT}}$ : the power density relaxed from the vibrational to the translation energy level of $\mathrm{N}_{2} ; Q_{\mathrm{ET}}$ : the power density relaxed from electronically excited levels as well as from dissociation and ionization of $\mathrm{N}_{2}$ molecules; $\tau_{\mathrm{VT}}$ and $\tau_{\mathrm{ET}}$ : time scales of the vibrational relaxation and the electronic relaxation in $\mathrm{N}_{2} ; Q_{\text {in }}$ and $Q_{\text {out }}$ : the local power input and output density; $\varepsilon$ : the total energy density; $\varepsilon_{\mathrm{V}}$ : the vibrational energy density; $\varepsilon_{\mathrm{E}}$ : the sum of the electronic excited energy and energy spent on ionization of $\mathrm{N}_{2} ; p \cdot \mathrm{dV}$ : gas dynamics contribution to the total energy density.

\subsection{Streamer-to-spark transition phase}

The breakdown electric field in $\mathrm{N}_{2}$ is normally $E_{\mathrm{b}}=20 \mathrm{~N} / \mathrm{N}_{0}$ $\mathrm{kV} \mathrm{cm}^{-1}$ [44], in which $N_{0}$ is the density under standard temperature and pressure (STP) and $N$ is the density at working pressure. Since the electric field applied in this work is lower than $E_{\mathrm{b}}$, the streamer mechanism is applicable in our model. Streamer properties like radius, maximum field on tip, propagation velocity, electron density distribution, etc, have been very well studied [39, 45-47]. Results of previous work $[48,49]$ in streamer propagation are taken as input parameters for our modeling. In $[50,51]$ scaling (or similarity) laws have been derived. We use these laws to obtain streamer properties in SC $\mathrm{N}_{2}$ by scaling of literature values at STP. However, as corrections to the scaling law at pressure substantially above 1 bar have been suggested in [75], and as the electrodynamic radius of the discharge channel briefly after the streamer phase has been measured to be $35 \mu \mathrm{m}$, we use $35 \mu \mathrm{m}$ as the initial radius. The streamer develops into a conducting channel and electric energy from the external source, with power density denoted as $Q_{\mathrm{R}}$, deposits into the channel. When the $\mathrm{N}_{2}$ temperature in the channel heats up to $T_{\mathrm{g}}=5000 \mathrm{~K}[19,20]$, we move to the next modeling domain: the discharge $\&$ postdischarge phase.
$Q_{\mathrm{R}}$ is composed of the ion and electron contributions, denoted as $Q_{\text {ion }}$ and $Q_{\text {e }}$ respectively. The ion component of the energy is neglected, as for the time scales considered in the present work ion mobility is negligible compared to the electron mobility. So the electric energy input is considered to be equal to the electron component of the electric energy $Q_{\mathrm{R}}=Q_{\mathrm{e}}$. After the streamer bridges the gap, the electric field $E$ is assumed to be uniform in the gap [52]. For a given $E$, the electron energy deposition rate can be calculated with the equation $Q_{\mathrm{e}}=\sigma_{\mathrm{e}} E^{2}=q_{\mathrm{e}} \mu_{\mathrm{e}} n_{\mathrm{e}} E^{2}$, where $\sigma_{\mathrm{e}}$ is the electrical conductivity due to electron mobility; $q_{\mathrm{e}}, \mu_{\mathrm{e}}$ and $n_{\mathrm{e}}$ are the electron charge, mobility and number density of electrons, respectively.

The electron mobility $\mu_{\mathrm{e}}$ is dependent on the reduced electric field $E / n_{\mathrm{N}_{2}}$ and was obtained from [53]. The balance of the electron density $n_{\mathrm{e}}$ can be analyzed through the kinetic processes governing the species reactions such as direct ionization, step-wise and associative ionization, attachment, detachment, etc. In the present work we consider only the ionization and recombination mechanism. We write the kinetic equation in the following form:

$$
\frac{\mathrm{d} n_{\mathrm{e}}(r)}{\mathrm{d} t}=n_{\mathrm{N}_{2}}(r) n_{\mathrm{e}}(r) F_{\mathrm{ion}}(r)-n_{\mathrm{e}}(r) n_{+}(r) F_{\mathrm{rec}}(r)
$$




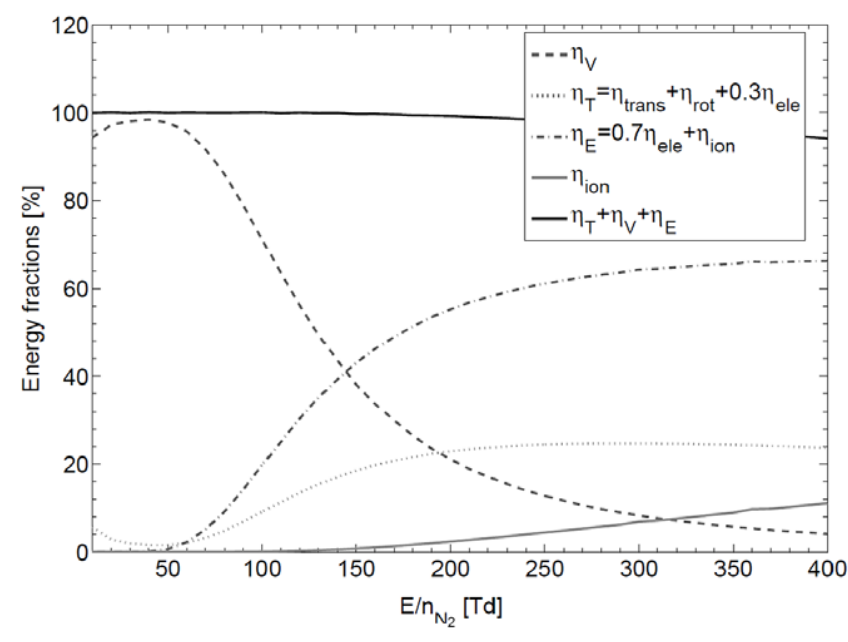

Figure 12. Energy fractions for discharge in $\mathrm{N}_{2}$ as a function of reduced electric field $E / n_{\mathrm{N}_{2}} ; \eta_{\text {trans }}$ : fractions of energy that go into the translational level, $\eta_{\text {rot }}$ : the rotational level, $\eta_{\mathrm{V}}$ : the vibrational level, $\eta_{\text {ele }}$ : the electronic excited level and $\eta_{\text {ion }}$ : the ionization of $\mathrm{N}_{2}$.

where $F_{\text {ion }}(r)\left(\mathrm{m}^{3} \mathrm{~s}^{-1}\right)$ and $F_{\text {rec }}(r)\left(\mathrm{m}^{6} \mathrm{~s}^{-1}\right)$ are the ionization and recombination coefficients of $\mathrm{N}_{2}$, obtained from $[53,54]$. In the appendix we use a zero-dimensional model to analyze detailed temporal dynamics of the species in a streamer channel. The results reveal that during the discharge $\mathrm{N}_{2}^{+}$ is converting very rapidly to $\mathrm{N}_{4}^{+}$, and the dominant electron loss mechanism in the streamer channel is the electron-ion dissociative recombination between $\mathrm{N}_{4}^{+}$and electrons [57]. In equation (6) the drift and diffusion of the electrons and ions are justified to be neglected in the nanosecond time range in our situation. We mention here a discussion with a referee about the assumption that the electron density is uniform along the streamer channel after the streamer bridges the gap. The referee refers to [58], stating that the electrons would be rapidly lost due to recombination at high pressure. The motivation of [58] that streamers would not obey scaling relations with pressure [59], can be resolved by taking the scaling of streamer lengths with pressure into account. Furthermore in [58] it is implicitly assumed that the gas stays weakly ionized, whereas according to our calculations the gas is highly ionized (40\%), therefore the ground state recombination rates suggested in [58] do not apply. In the present paper we have chosen the simplified 1D approximation and refer to our future work for a 2D model.

As described before, part of the discharge power density $Q_{\mathrm{R}}$ is transferred into the excited levels and needs time to relax. Figure 12 gives the fractions of energy that go into translational level $\eta_{\text {trans }}$, rotational level $\eta_{\text {rot }}$, vibrational level $\eta_{\mathrm{V}}$, electronic excited level $\eta_{\text {ele }}$, and ionization of $\mathrm{N}_{2} \eta_{\text {ion }}$, as a function of the reduced electric field $E / n_{\mathrm{N}_{2}}$ obtained from BOLSIG+ [55]. Flitti and Pancheshnyi [56] reported insignificant sensitivity of the energy fractions to pressure changes, so figure 12 is considered to be applicable for the SCF situation. From the figure we can see that the sum of energy fractions equals $100 \%$ in the range of electric field concerned, which indicates that all the energy has been taken into account.

The fraction of energy expended on translational level $\eta_{\text {trans }}$ and rotational level $\eta_{\text {rot }}$ can be considered to equilibrate instantaneously [19-21,60]. In a large range of reduced electric fields $E / n_{\mathrm{N}_{2}}=60-300 \mathrm{Td}$, about $30 \%$ of the energy expended on the excitation of electronic levels with fraction $\eta_{\text {ele }}$ is directly transferred to gas heating [20,21, 60,61]. The main source of $\mathrm{N}$ atoms is via the routes of electronic excitation and subsequent dissociation [61,62]. This implies that the fraction $\eta_{\text {ele }}$ already contains the electron induced production of atoms (dissociation); $30 \%$ is directly converted to heat (heat release in dissociative de-excitation), $70 \%$ is delayed (heat release in de-excitation and atom recombination). The fraction of the energy which goes into vibrational excited level $\eta_{\mathrm{V}}$ also needs time to be relaxed to gas heating. This process is known as a vibrational relaxation with time constant $\tau_{\mathrm{VT}}$. Depending on the applied reduced electric field $E / n_{\mathrm{N}_{2}}$, a small fraction $\eta_{\text {ion }}$ of energy is expended on the ionization of $\mathrm{N}_{2}$ molecules. This fraction is found to be $\eta_{\text {ion }} \leqslant 2.5 \%$ for a value of $E / n_{\mathrm{N}_{2}} \leqslant 200 \mathrm{Td}$. The energy expended for ionization together with the remaining $70 \%$ of the electronic excited energy, whose sum we denote by $\eta_{\mathrm{E}}=\eta_{\text {ion }}+0.7 \eta_{\text {ele }}$, takes time to be relaxed to the gas heating, which is a complicated process [61]. For the sake of simplicity, we do not track the detailed processes such as dissociative ionization, dissociative recombination, atomic recombination, etc. Instead we assume that this part of the energy will be relaxed into gas heating with an assumed time constant $\tau_{\mathrm{ET}}$.

In summary, the discharge energy that goes directly into gas heating can be expressed as equation

$$
Q_{\mathrm{T}}=\eta_{\mathrm{T}} Q_{\mathrm{R}},
$$

with the fraction of energy contributing directly to the gas heating $\eta_{\mathrm{T}}$ written as

$$
\eta_{\mathrm{T}}=\eta_{\mathrm{trans}}+\eta_{\mathrm{rot}}+0.3 \eta_{\mathrm{ele}}
$$

The discharge energy that relaxes from the vibrational level to gas heating is expressed with equation

$$
Q_{\mathrm{VT}}=\frac{\varepsilon_{\mathrm{V}}-\varepsilon_{\mathrm{V}, \mathrm{eq}}\left(T_{\mathrm{g}}\right)}{\tau_{\mathrm{VT}}},
$$

in which $\varepsilon_{\mathrm{V} \text {,eq }}\left(T_{\mathrm{g}}\right)\left(\mathrm{J} \mathrm{m}^{-3}\right)$ is the equilibrium value of $\varepsilon_{\mathrm{V}}$ at temperature $T_{\mathrm{V}}=T_{\mathrm{g}}$ given by the following expression [65]:

$$
\varepsilon_{\mathrm{V}, \mathrm{eq}}\left(T_{\mathrm{g}}\right)=n_{\mathrm{N}_{2}} \cdot \frac{\Delta E_{\mathrm{V}}}{\mathrm{e}^{\Delta E_{\mathrm{V}} / k_{\mathrm{B}} \cdot T_{\mathrm{g}}}-1},
$$

and the time scales of the vibrational relaxation $\tau_{\mathrm{VT}}$ in $\mathrm{N}_{2}$ can be written as $[63,64]$

$$
\tau_{\mathrm{VT}}=\left(p_{\mathrm{g}} / 10^{5}\right)^{-1} \cdot 3.4 \times 10^{-12} \mathrm{e}^{195 \times T_{\mathrm{g}}^{-1 / 3}} .
$$

In the equations above $\triangle E_{\mathrm{V}}$ is the vibrational energy of one $\mathrm{N}_{2}$ molecule and is equal to $0.29 \mathrm{eV}$; $k_{\mathrm{B}}$ is Boltzmann's constant $k_{\mathrm{B}}=1.38 \times 10^{23} \mathrm{~J} \mathrm{~K}^{-1} ; p_{\mathrm{g}}$ is the gas pressure $(\mathrm{Pa})$. The discharge energy that relaxes from the electronic excited level as well as releases by recombination mechanisms is expressed by equation

$$
Q_{\mathrm{ET}}=\varepsilon_{\mathrm{E}} / \tau_{\mathrm{ET}}
$$

in which $\varepsilon_{\mathrm{E}}=\int_{0}^{t} \eta_{\mathrm{E}}(\tau) Q_{\mathrm{R}} \mathrm{d} \tau$ is the integrated energy with fraction $\eta_{\mathrm{E}}$ over the simulation time $\tau$. [54] reported the 
relaxation of electronic-excited $\mathrm{N}_{2}$ within $20 \mu \mathrm{s}$ in air discharge under ambient pressure, and the relaxation time tends to be smaller in higher density gas [66]. Since the modeling result is found to be insensitive to the precise value of $\tau_{\mathrm{ET}}$, we assume the relaxation time to be $\tau_{\mathrm{ET}}=20 \mu \mathrm{s}$.

Around the axis of the spark channel, the heat transfer is dominated by radiation [67]. We split the channel into infinitively thin annular zones with thickness $\delta r$, whose volume calculated to be $V=\pi \delta r^{2} \cdot d$. The selection of $\delta r$ will be described later in section 3.4. The heat transfer by radiation can be expressed by

$$
Q_{\mathrm{rad}}=\xi \cdot \sigma \frac{\left(T_{\mathrm{g}}^{4}-T_{\mathrm{N} 2}^{4}\right) \cdot S}{V},
$$

where $\xi$ is the net emission factor dependent on the gas temperature and pressure in the discharge zone, $\sigma=5.671 \times 10^{-8} \mathrm{~W} \mathrm{~m}^{-2} \mathrm{~K}^{-4}$ Stefan-Boltzmann constant, $T_{\mathrm{N} 2}=300 \mathrm{~K}$ the environmental temperature, and $\mathrm{S}=2 \pi \mathrm{r} \cdot \mathrm{d}$ the radiation surface area. The expression of $\xi$ is taken from [67] and reads

$$
\xi=1-\mathrm{e}^{-\left(\mathrm{C} \cdot p_{\mathrm{g}}^{1.2} r^{0.5}\right) / T_{\mathrm{g}}},
$$

where $\mathrm{C}$ is a constant $\mathrm{C}=4.2 \times 10^{-3} \mathrm{~Pa}^{-1.2} \mathrm{~m}^{-0.5} \mathrm{~K}$. This expression of $\xi$ is valid for $\mathrm{SF}_{6}$, but since we assume the spark channel reaches local thermal equilibrium (LTE) soon (details seen in section 3.3), the difference of $\xi$ for $\mathrm{SF}_{6}$ and $\mathrm{N}_{2}$ is considered to be not significant.

Due to the faster temperature rise in the inner discharge channel, there is a temperature gradient in the radial direction. Energy is transferred by heat conduction from the high temperature to low temperature gas by expression

$$
Q_{\mathrm{cond}}=-k \cdot \frac{\partial T_{\mathrm{g}}}{\partial r} \frac{2 \pi r d}{\pi\left(r_{j+1}^{2}-r_{j}^{2}\right) d},
$$

where $k\left(\mathrm{~W} \mathrm{~m}^{-1} \mathrm{~K}^{-1}\right)$ represents the thermal conductivity of the $\mathrm{N}_{2} ; r_{j}$ and $r_{j+1}$ are the inner and outer radius of the annular zones, with relation $r_{j+1}=r_{j}+\delta r$. In this stage the thermodynamic parameters of the SCF below $2000 \mathrm{~K}$ are calculated precisely with [10], while above this temperature no existing references can be found. However, from [68] we can find that for temperatures above $2000 \mathrm{~K}$, the thermal conductivity of the gas is almost independent of the gas pressure, i.e. $k$ keeps almost constant with increasing $p_{\mathrm{g}}$. So for temperature higher than $2000 \mathrm{~K}, k$ is calculated from the equation in air [69] and assumed to be applicable for the SC $\mathrm{N}_{2}$ situation. Hence the thermal conductivity $k$ of $\mathrm{N}_{2}$ can be expressed by equation

$$
k=\left\{\begin{aligned}
14.88 \sigma T_{\mathrm{g}}+2.2 \times 10^{8} \rho \frac{\mathrm{d} A_{0}}{\mathrm{~d} T_{\mathrm{g}}} & \\
+0.01\left(1-A_{1}\right) \sqrt{T_{\mathrm{g}},} & T_{\mathrm{g}} \geqslant 2000 \mathrm{~K}, \\
k^{0}\left(T_{\mathrm{g}}\right)+k^{r}(\tau, \delta)+k^{c}(\tau, \delta), & T_{\mathrm{g}}<2000 \mathrm{~K},
\end{aligned}\right.
$$

where the detailed description of dimensionless numbers $A_{0}$, $A_{1}$ as well as the sub-terms of thermal conductivity $k^{0}\left(T_{\mathrm{g}}\right)$, $k^{r}(\tau, \delta), k^{c}(\tau, \delta)$ can be found in $[10,69]$.

Energy loss to the metal electrodes (parts 1, 2 and 5 in figure 2) by heat conduction is considered in our model. Since the system is axially symmetric, we calculate the heat transfer to the anode side and multiply the results by 2 to get the value of heat transfer to electrodes $Q_{\text {electrode. The equation }}$ is formulated as

$$
Q_{\text {electrode }}=\frac{2\left(T_{\mathrm{g}}-T_{\infty}\right)}{R_{\text {heat }}} \cdot \frac{1}{\pi\left(r_{j+1}^{2}-r_{j}^{2}\right) d},
$$

in which $T_{\infty}=300 \mathrm{~K}$ is the electrode temperature on the far distance surface; $R_{\text {heat }}\left(\mathrm{m}^{2} \mathrm{~W}^{-1}\right)$ is the total thermal resistance of the spark channel, the electrode head (part 2 in figure 2), and the electrode body (part 1 in figure 2). The equation of $R_{\text {heat }}$ can be written as

$$
R_{\text {heat }}=\left(\frac{1 / 4 d}{k}+\frac{L_{1}}{k_{1}}+\frac{L_{2}}{k_{2}}\right) \cdot \frac{1}{\pi\left(r_{j+1}^{2}-r_{j}^{2}\right)},
$$

in which the characteristic lengths of the thermal resisting layers are respectively $1 / 4 d$ for the high temperature spark, $L_{1}=10 \mathrm{~mm}$ for the electrode head, and $L_{2}=126 \mathrm{~mm}$ for the electrode body; the thermal conductivity of the layers are respectively $k$ obtained from equation (16) for the high temperature medium, $k_{1}=189$ for the electrode head, and $k_{2}=21$ for the electrode body.

\subsection{Discharge \& post-discharge phase}

In the discharge \& post-discharge stage the spark channel expands due to the pressure rise and shock waves form under the combined changes of the kinetic and heat energy. The total energy of the spark channel decreases and the channel cools down. The dielectric characteristics of the gas are restored and finally the thermal recovery of the gap will be complete.

Many works have discussed the modeling of the spark discharge in this stage based on different mechanisms. Taylor [70] and Lin [71] modeled the strong shock wave generated with an infinitely small initial radius. The similarity assumptions of an expanding blast wave of a constant total energy are applied and the heat transfer term is ignored. Authors used Rankine-Hugoniot relations to calculate the parameter profiles versus time and radius. Plooster [69] estimated the blast wave from line sources, in which the conservation of momentum, mass and internal energy are applied. For the energy conservation, heat exchange between the blast wave and the environment is neglected. Akram $[29,30]$ developed the hydrodynamic equations by adding heat transfer terms and correcting the momentum equation in Plooster's work. In both Plooster and Akram's work, artificial viscosity from von Neumann-Richtmyer [72] is implemented in the models in order to solve the discontinuity problem in the shock region.

In our model since the profile of the parameters is already known from the results of the previous stages, the artificial viscosity term is not needed in the modeling. Compared to the models of Plooster and Akram, the equation of conservation of energy in this model has additional terms of energy relaxation from excited levels to the neutral gas heating. Following the assumptions made by Akram, we assume that LTE exists all the time; the discharge column is straight and cylindrical 
Table 1. The initial parameters for the model.

\begin{tabular}{llll}
\hline Parameter & Symbol & Value at ground pressure & Scaling property \\
\hline Electron mobility & $\mu_{\mathrm{e}, 0}$ & $\sim 4.4 \times 10^{-2} \mathrm{~m}^{2} \mathrm{~V}^{-1} \mathrm{~s}^{-1}$ & $\propto\left(N / N_{0}\right)^{-1}$ \\
Initial gas temperature & $T_{\mathrm{N}_{2}}$ & $300 \mathrm{~K}$ & $\propto\left(N / N_{0}\right)^{0}$ \\
Initial vibrational temperature & $T_{\mathrm{V}, 0}$ & $300 \mathrm{~K}$ & $\propto\left(N / N_{0}\right)^{0}$ \\
Quantum of vibrational energy & $\triangle E_{\mathrm{V}}$ & $0.29 \mathrm{eV}$ & $\propto\left(N / N_{0}\right)^{0}$ \\
Applied voltage & $V$ & $30 \mathrm{kV}$ & $\propto\left(N / N_{0}\right)^{0}$ \\
Gap distance & $d$ & $24.3 \mathrm{~mm}$ & $\propto\left(N / N_{0}\right)^{-1}$ \\
Initial gas density & $n_{\mathrm{N}_{2}, 0}$ & $2.4 \times 10^{25} \mathrm{~m}^{-3}$ & $\propto\left(N / N_{0}\right)^{1}$ \\
Initial electron density & $n_{\mathrm{e}, 0}$ & $8.87 \times 10^{20} \mathrm{~m}^{-3}[74]$ & $\propto\left(N / N_{0}\right)^{2}$ \\
Initial channel radius & $r_{\mathrm{s}, 0}$ & $100 \mu \mathrm{m}[75]$ & $\propto\left(N / N_{0}\right)^{-1}$ \\
\hline
\end{tabular}

Table 2. Numerical settings of the modeling.

\begin{tabular}{lll}
\hline Parameter & Symbol & Value \\
\hline Initial domain size & $L_{\mathrm{r}, 0}$ & $10 \times r_{\mathrm{s}, 0}$ \\
Initial space step & $\delta r_{0}$ & $r_{\mathrm{s}, 0} / 100$ \\
Space step & $\delta \mathrm{r}$ & $\propto 1 / \rho$ \\
Domain size & $L_{\mathrm{r}}$ & $\sum \delta r$ \\
Time step & $\delta t$ & $0.01 \times \min \left(\delta r / a, \tau_{\mathrm{VT}}\right)$ \\
\hline
\end{tabular}

Note: $a$ is the sound velocity inside SCF.

symmetric; the conduction portion of the plasma column is electrically neutral; the interactions of the discharge current and its own magnetic field as well as the body forces are negligible.

The hydrodynamic equations in this stage can be expressed again by the formula (3). The electric power input $Q_{\mathrm{R}}$ with the same expression as the previous section is assumed to exclusively contribute to the gas heating, i.e. $Q_{\mathrm{T}}=Q_{\mathrm{R}}$. The fraction of energy transferred into vibrational excited and electronic excited levels in formula (3) is now set to be $\eta_{\mathrm{V}} Q_{\mathrm{R}}=\eta_{\mathrm{E}} Q_{\mathrm{R}}=0$. Energy previously stored in the excited levels continues to be relaxed into gas heating by the terms $Q_{\mathrm{VT}}$ and $Q_{\mathrm{ET}}$, with time constant $\tau_{\mathrm{VT}}$ and $\tau_{\mathrm{ET}}$ respectively, as given in equations (9)-(12). The heat radiation $Q_{\text {rad }}$, heat conduction in $\mathrm{N}_{2} Q_{\text {cond }}$ and heat conduction to electrodes $Q_{\text {electrode }}$ can again be expressed by equations (13)-(18).

Thermal dissociation and ionization of $\mathrm{N}_{2}$ molecules become significant under high gas temperature. However, in our simulation the high temperature zone vanishes with a time scale much shorter than the establishing time of dissociation and ionization equilibrium. Hence we neglect the impact of thermal dissociation and ionization in our simulation. A detailed discussion will be given in section 4 .

\subsection{Numerical conditions}

The initial values of the input parameters are adapted from streamer modeling results mentioned in section 3.2. Table 1 gives the initial parameters at STP as well as the corresponding scaling properties. The initial parameters at the working pressure in this paper, $80.9 \mathrm{bar}$, are calculated from the values given in table 1 .

We assume in the radial direction the initial electron density $n_{\mathrm{e}}(r, t)$ has a Gaussian shape

$$
n_{\mathrm{e}}(r, 0)=n_{\mathrm{e}, 0} \cdot \mathrm{e}^{-r^{2} / r_{\mathrm{s}, 0}^{2}},
$$

where $r_{\mathrm{s}, 0}$ and $n_{\mathrm{e}, 0}$ are the initial channel radius and the maximum electron density on the axis of the channel. Initial $\mathrm{N}_{2}$ density, velocity and pressure are assumed to be constant from table 1 . The system (3) is discretized using a second-order Lax-Wendroff numerical scheme [73], with the numerical parameters presented in table 2 .

\section{Results and discussions}

\subsection{General results}

The experimental results in figure 5 show that within $1 \mathrm{~ms}$, depending on the $p$ and $d$ setting, $U_{\mathrm{bd}}$ recovers to about 20-30 kV. The experimental results of the SC switch under repetitive pulses with the time lag of $1 \mathrm{~ms}$ prove that the breakdown voltage and the recovery percentage of SCF increase with higher $p d$, whilst a too small gap width $d \leqslant$ $0.2 \mathrm{~mm}$ deteriorates the recovery percentage of the switch. Figures 5 and 6 show an interesting phenomenon distinguished by the value of $p d$. For $p d$ less than 20 bar mm, a larger gap width $d$ contributes to faster recovery, while the contribution of larger $d$ to $U_{\mathrm{bd}}$ is not that obvious. For $p d$ larger than 20 bar $\mathrm{mm}$, the effect of $d$ on the recovery percentage vanishes while on $U_{\text {bd }}$ becomes more significant. Under the situation of $d>0.2 \mathrm{~mm}$, the recovery percentage of the SC switch achieves $80 \%$ within $1 \mathrm{~ms}$, when the parameters are set to be $p d \geqslant 18$ bar mm.

The modeling results based on the initial parameters defined in section 3.4 are given as below. Figure 13 gives the results of neutral $\mathrm{N}_{2}$ temperature $T_{\mathrm{g}}$ and vibrational temperature $T_{\mathrm{V}}$ on the axis of the spark channel in the early stage of the discharge. The phenomenon that $T_{\mathrm{V}}$ increases faster than $T_{\mathrm{g}}$ is due to the larger fraction of energy stored in the vibrational level than in the translational level. At a time of $1.5 \mathrm{~ns}, T_{\mathrm{g}}$ heats up to $5000 \mathrm{~K}$, while $T_{\mathrm{V}}$ has a value of about $18000 \mathrm{~K}$. The time needed for $T_{\mathrm{g}}$ heating up to $5000 \mathrm{~K}$ decreases with increasing the reduced electric field, and for the same value of reduced electric field, higher $E$ and $p$ result in a shorter formation time than lower $E$ and $p$. Following Toepler's spark law [76], the time dependent resistance of the spark channel can be calculated with equation

$$
R_{\mathrm{F}}(t)=\frac{k_{\mathrm{T}} d}{\int_{0}^{t} i(\tau) \mathrm{d} \tau},
$$

in which $i(t)$ is the measured current across the gap, $R_{\mathrm{F}}(t)$ $(\Omega)$ the resistance of the spark channel at time point $t, k_{\mathrm{T}}$ the 


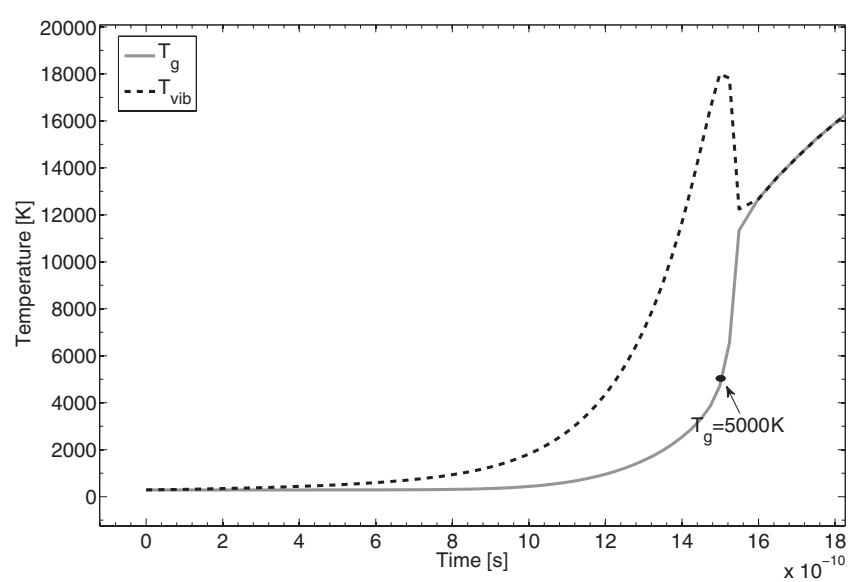

Figure 13. Gas temperature and vibrational temperature on the spark axis in the streamer-to-spark transition stage. Initial parameters seen in section 3.4.

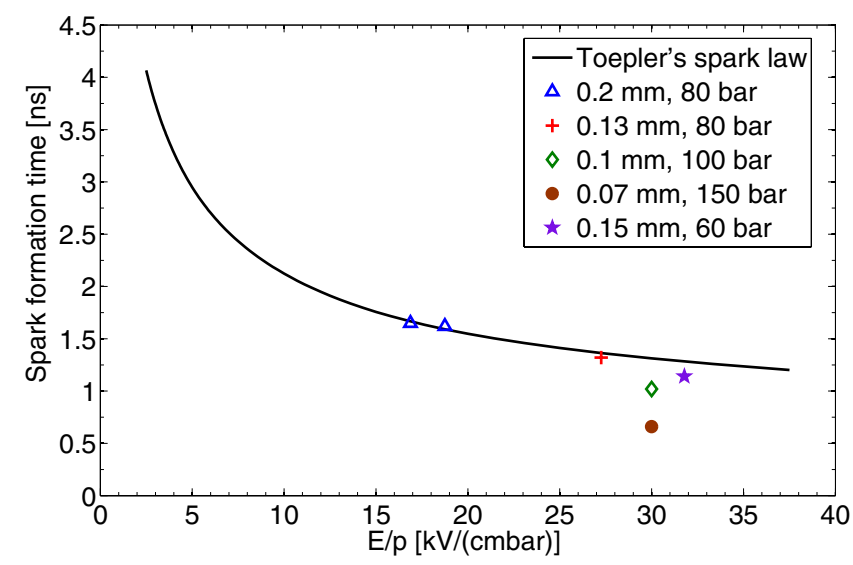

Figure 14. Streamer-to-spark transition time calculated by Toepler's law [76] and modeling results with different $p, d$ settings in the present paper.

empirical spark constant, and $d$ the gap length. The spark is assumed to be formed when $R_{\mathrm{F}}(t) \leqslant 100 \Omega$, which is the moment we denote as the spark formation time. Figure 14 gives the calculated spark formation time as a function of the reduced electric field $E / p$, as well as the time needed for gas temperature building to $T_{\mathrm{g}} \geqslant 5000 \mathrm{~K}$ according to our simulation results. The time needed for $T_{\mathrm{g}} \geqslant 5000 \mathrm{~K}$ in our model matches well with the spark formation time calculated from Toepler's law, while disparity appears when $d \leqslant 0.1 \mathrm{~mm}$, and with smaller gap width, this disparity becomes more significant.

Simultaneously with the temperature rise, the $\mathrm{N}_{2}$ pressure $p_{\mathrm{g}}$ also increases in the discharge channel. Figure 15 gives the ratio of the pressure on the axis of the discharge to the background pressure $p_{\text {axis }} / p_{\text {back }}$. From equation (11) we can see that the value of vibrational energy relaxation time $\tau_{\mathrm{VT}}$ decreases with increasing $T_{\mathrm{g}}$ and $p_{\mathrm{g}}$. With smaller $\tau_{\mathrm{VT}}$, the energy relaxes faster from vibrational level to gas heating. From figure 13 it is clear that immediately after the spark is formed, $T_{\mathrm{V}}$ starts to decrease while $T_{\mathrm{g}}$ increases more dramatically, and they merge with each other at $\sim 1.6 \mathrm{~ns}$, $T_{\mathrm{V}}=T_{\mathrm{g}}=13000 \mathrm{~K}$. LTE status is assumed to be achieved at this moment. Since this time is almost the same as the

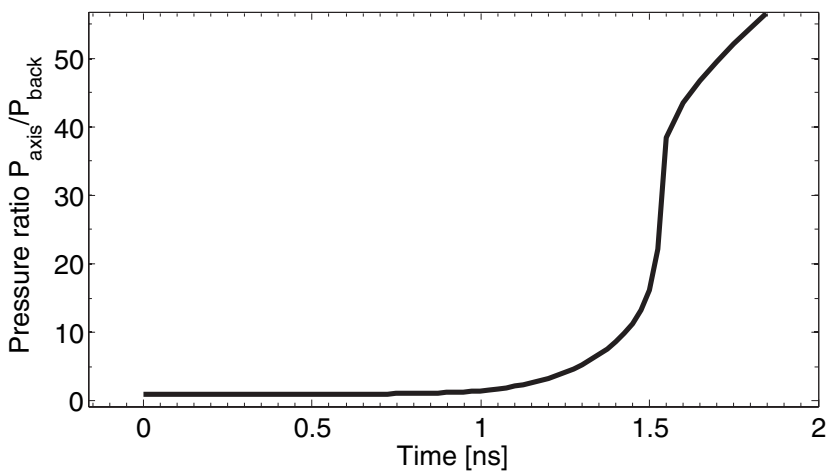

Figure 15. $\mathrm{N}_{2}$ pressure increase on the axis of the spark channel; $P_{\text {axis }}: \mathrm{N}_{2}$ pressure on the axis; $P_{\text {back }}=80.9$ bar: background $\mathrm{N}_{2}$ pressure.

time needed for $T_{\mathrm{g}} \geqslant 5000 \mathrm{~K}$, the assumption of LTE during the modeling of the discharge \& post-discharge stage is fairly accurate.

Figure 16 gives the radial distributions of the $\mathrm{N}_{2}$ temperature $T_{\mathrm{g}}$, the neutral partial velocity $u$, the $\mathrm{N}_{2}$ density $\rho_{\mathrm{g}}$, and the ratio of $\mathrm{N}_{2}$ pressure to the background pressure $p_{\mathrm{g}} / p_{\text {back }}$, at various time instants after the streamer bridges the gap, denoted as $t_{\mathrm{d}}$. It can be seen that $T_{\mathrm{g}}$ in the discharge channel heats up to $21000 \mathrm{~K}$ at $t_{\mathrm{d}}=3 \mathrm{~ns}$, while the $\rho_{\mathrm{g}}$ in the channel does not show a significant change. The pressure $p_{\mathrm{g}}$ in the channel builds up rapidly due to the unchanged $\rho_{\mathrm{g}}$ and increased $T_{\mathrm{g}}$.

Later on the temperature curve becomes broader and flatter. In the meantime the $\mathrm{N}_{2}$ moves outwards with increasing peak velocity $u$ which becomes supersonic at the time of $49 \mathrm{~ns}$. Shock waves form after the extinction of the electric energy input, i.e. after $t_{\mathrm{d}}=220 \mathrm{~ns}$. The distribution of the gas density $\rho_{\mathrm{g}}$ changes so that $\rho_{\mathrm{g}}$ in the center of the channel becomes smaller, while high density exists in the shock region. The pressure at the shock boundary is an order of magnitude higher than that of the background pressure. From about $10 \mu \mathrm{s}$ onward, $T_{\mathrm{g}}$ in the whole discharge channel is below $1500 \mathrm{~K}$, and the $T_{\mathrm{g}}$ decay versus time becomes slower. This is because the gas does not transport much energy by heat conduction, due to the flatter temperature profile and smaller thermal conductivity. The shock wave propagates further during this time region. The gas density $\rho_{\mathrm{g}}$ in the channel recovers to the background density. The peak values of velocity $u$, the gas density $\rho_{\mathrm{g}}$, and pressure $p_{\mathrm{g}}$ propagate together with the shock wave and decrease with time. From $t_{\mathrm{d}} \approx 20 \mu \mathrm{s}$ onward, the temperature decay becomes very slow. The peak temperature in the channel is about $800 \mathrm{~K}$ at $t_{\mathrm{d}}=50 \mu \mathrm{s}$. From the microsecond time range on, the temperature on the axis of the discharge is lower than the temperature further from the axis. This might be due to the implementation of the net emission coefficient in equation (14) in the annular zones inside the channel. From $50 \mu$ s onward, the temperature on the axis of the spark channel is higher again than the temperature on the outer region of the spark channel. This is probably due to the fact that after $50 \mu$ s the system is equilibrated, and strong gradient effects like the non-monotonic temperature profile disappear. 

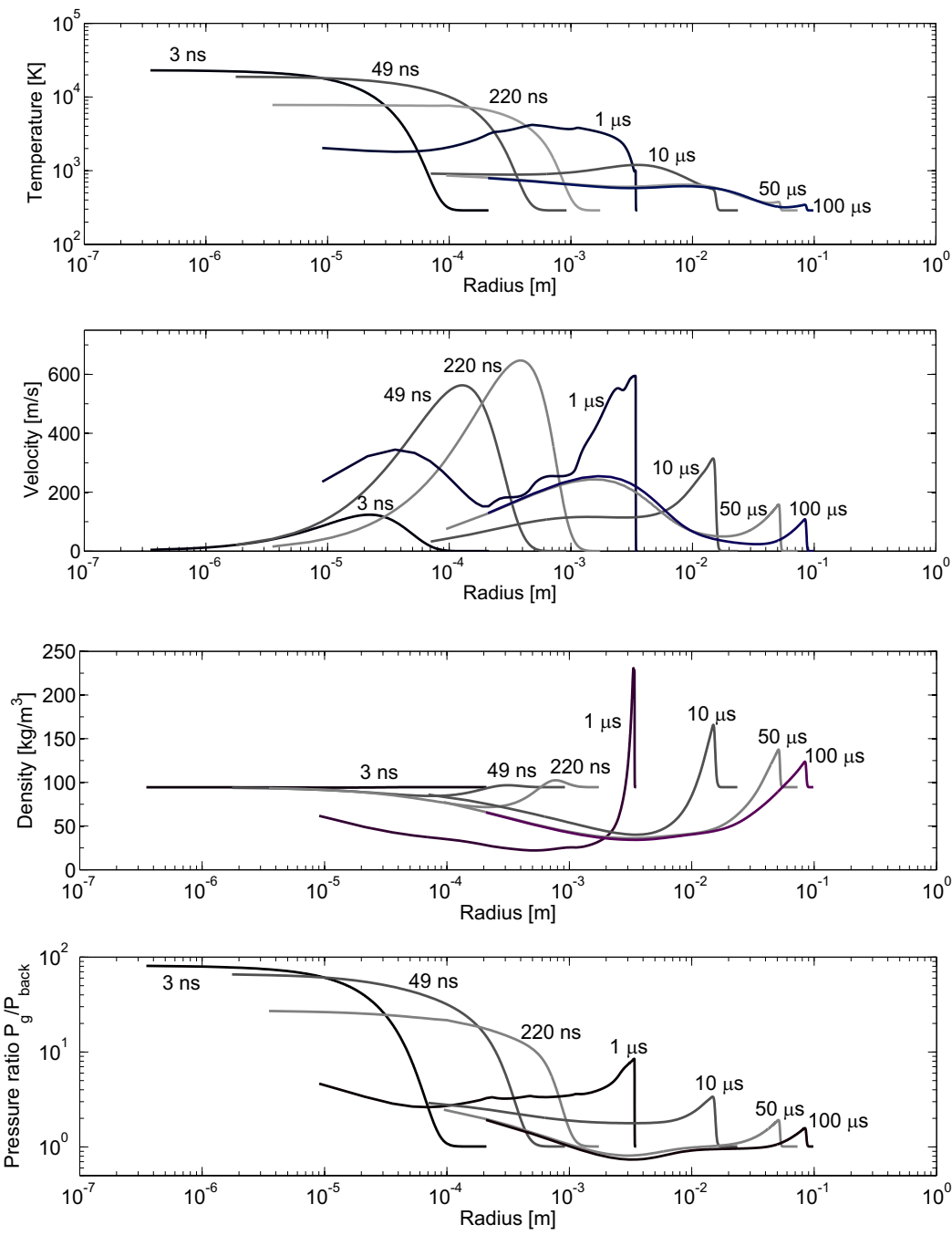

Figure 16. Parameters of the $\mathrm{N}_{2}$ temperature $T_{\mathrm{g}}$, velocity $\mathrm{u}$, density $\rho_{\mathrm{g}}$ and pressure ratio to the background pressure $P_{\mathrm{g}} / P_{\text {back }}$, in the radial coordinate of the spark channel at different moment after the streamer bridges the switch gap.

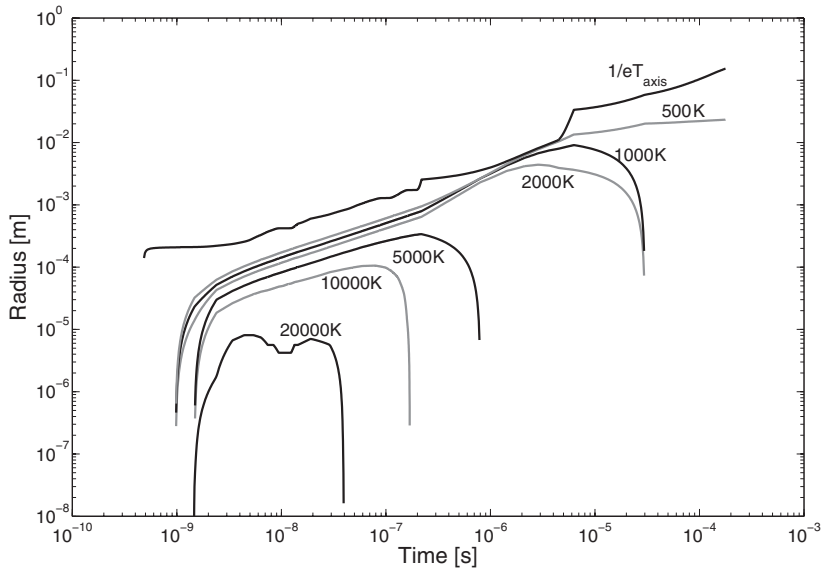

Figure 17. Radius of spark channel with the region defined as temperature above $1 / e \cdot T_{\text {axis }}, 500 \mathrm{~K}, 1000 \mathrm{~K}, 2000 \mathrm{~K}, 5000 \mathrm{~K}$, $10000 \mathrm{~K}$ and $20000 \mathrm{~K}$ respectively.

The distance of the shock wave is several centimeters away from the discharge axis. Comparing the observed millimeter shock region in experimental work with $60 \mathrm{kV}$ in a $50 \mathrm{~mm}$ gap under atmospheric pressure [77], the propagation of the shock front in our work is further from the axis. One of the important reasons is explained here. The experiment in a $\mathrm{N}_{2}$ discharge [78] shows that from tens of microsecond after the spark forms, the spark channel becomes a turbulent mix of excited and cold recirculating gases. The hydrodynamic instability of the gas due to the turbulent mixing would cause the compression of the spark channel [79], while in our simulation the turbulent mixing is missing. Besides, with turbulent mixing, the intensity of the channel cooling process will increase more sharply than by only taking into account heat transfer [79]. Since in our model the temperature decrease is already convincingly fast in the first $20 \mu$ s after the discharge, we do not take the turbulence energy transport into account. The reader should be aware that the recovery process of the SC $\mathrm{N}_{2}$ would be faster than the results shown by this model.

Figure 17 gives the modeling results of the high temperature region of the spark channel for $T_{\mathrm{g}}$ equal to: $1 / e \cdot T_{\text {axis }}, 500 \mathrm{~K}, 1000 \mathrm{~K}, 2000 \mathrm{~K}, 5000 \mathrm{~K}, 10000 \mathrm{~K}$ and $20000 \mathrm{~K}$ respectively. It can be seen that the kernel of the discharge for $T_{\mathrm{g}} \geqslant 20000 \mathrm{~K}$ shrinks after $40 \mathrm{~ns}$, whilst the $T_{\mathrm{g}}=1000 \mathrm{~K}$ boundary compresses after several tens of 


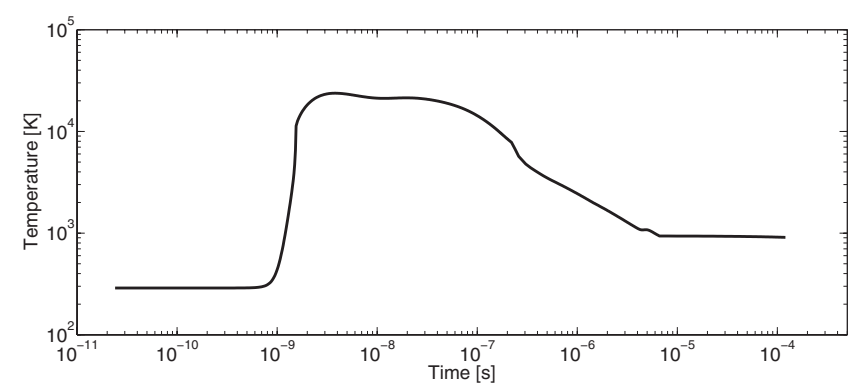

Figure 18. $\mathrm{N}_{2}$ temperature on the axis of the spark channel with $p d=24$ bar mm, $T_{\mathrm{N}_{2}}=300 \mathrm{~K}$ and $d=0.3 \mathrm{~mm}$.

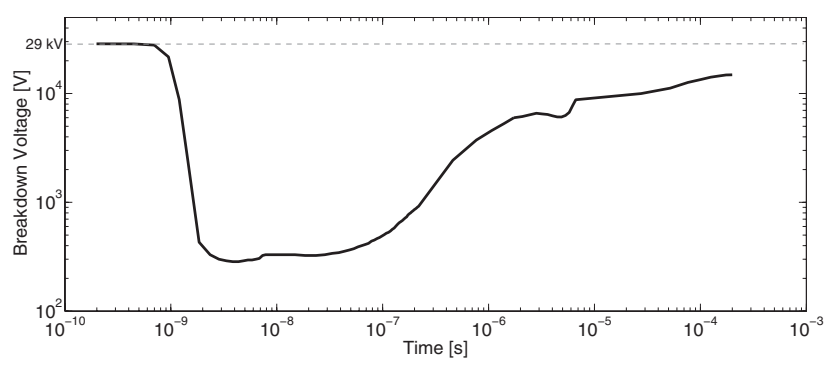

Figure 19. The recovery breakdown voltage of the $\mathrm{SC} \mathrm{N}_{2}$ with $p d=24$ bar mm, $T_{\mathrm{N}_{2}}=300 \mathrm{~K}$ and $d=0.3 \mathrm{~mm}$.

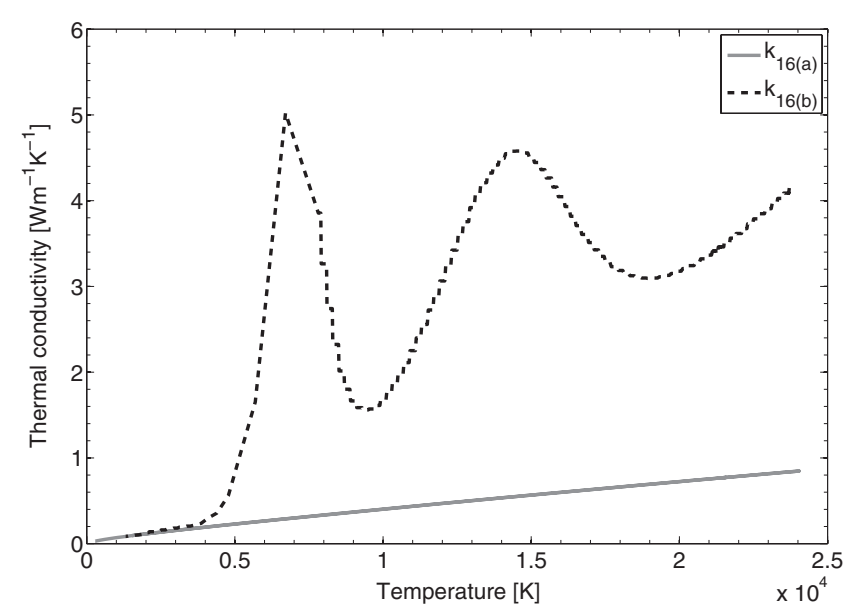

Figure 20. Thermal conductivity of $\mathrm{N}_{2}$ calculated with the two sub-equations in equation (16). Solid line-equation 16(a); dashed line-equation $16(b)$.

microseconds. The characteristic time needed for establishing the thermal ionization equilibrium for $\mathrm{N}_{2}$ at a temperature of $20000 \mathrm{~K}$ is in the range of about $1 \mu \mathrm{s}$ to $6 \mu \mathrm{s}$, as calculated with our specific initial electron density and the data given in [80]. For a temperature of $20000 \mathrm{~K}$, the fraction of thermally dissociated $\mathrm{N}_{2}$ is about $10^{-5}$ at a time of $1 \mu \mathrm{s}$, as reported in [81]. Since the time scale for establishing thermal dissociation and ionization equilibrium is much longer than the time duration of the high temperature zone in our modeling results, it is acceptable to exclude the two mechanisms from our model.

The $\mathrm{N}_{2}$ temperature on the axis of the spark channel $T_{\text {axis }}$ is plotted as the function of time, seen in figure 18. It can be seen that $T_{\text {axis }}$ drops to $1000 \mathrm{~K}$ at $6 \mu \mathrm{s}$. In order to transfer the information of temperature decay to the dielectric recovery of the SCF, the streamer inception criterion is applied. Here the concept will be briefly introduced. During the dielectric recovery process, at a certain external electric field across the gap, avalanches are initiated from those locations which have the highest reduced electric field $E / n_{\mathrm{N}_{2}}$ and start to propagate. These places could be either small protrusions on the electrode surface or the low density region of the discharge channel. Usually these are the hottest regions in the center of the channel, but with the varying pressure in the channel, in reality it might also be at the boundaries. If the avalanche attains a critical electron number $N_{\mathrm{e}, \mathrm{c}}$ within $x_{\mathrm{cr}} \leqslant d$, it leads to fast moving streamers from the avalanche head. These streamers can result in partial or complete breakdown in non-uniform field gaps. We calculate the breakdown voltage according to the discharge parameters on the axis, by assuming a streamer initiating from a semi-ellipsoid protrusion on the electrode surface. The major semi-axis of the protrusion is $20 \mu \mathrm{m}$, and the minor semi-axis $10 \mu \mathrm{m}$. The streamer inception criterion can be expressed as [82]

$$
\int_{0}^{x_{\mathrm{cr}}} \alpha[E(x)] \mathrm{d} x=\ln \left(N_{\mathrm{e}, \mathrm{c}}\right),
$$

in which $\mathrm{E}(\mathrm{x})$ is the electrical field at the distance $\mathrm{x}$ from the tip of the protrusion; $N_{\mathrm{e}, \mathrm{c}}$ is the critical number of electrons; $\alpha$ $\left(\mathrm{m}^{-1}\right)$ is the ionization coefficient dependent on $E / n_{\mathrm{N}_{2}}$, which is taken from BOLSIG+ [55] (a more detailed discussion can be found in [83]). The value of $\ln \left(N_{\mathrm{e}, \mathrm{c}}\right)$ for $\mathrm{N}_{2}$ is a function of $p d$, which can be calculated by the equation given in [84]

$\ln \left(N_{\mathrm{e}, \mathrm{c}}\right)$

$=\left\{\begin{array}{lc}13.4+1.74 \ln (p d) & 2 \times 10^{-3} \leqslant p d \leqslant 0.05 \text { bar cm } \\ 5.75-0.76 \ln (p d) & 0.05 \leqslant p d \leqslant 10 \text { bar cm. }\end{array}\right.$

The criterion of breakdown of the gap in this work is defined as: under an average electric field $E_{\mathrm{bd}}$, if equation (21) is satisfied at $x_{\mathrm{cr}} \approx d$, we say that the streamer can bridge the electrodes hence cause the breakdown of the whole gap. Figure 19 gives the calculated breakdown voltage $U_{\mathrm{br}}$ during the recovery process. The dielectric strength of the gap $U_{\text {br }}$ decreases from cold breakdown value $U_{\text {cold }}=29 \mathrm{kV}$ to about $300 \mathrm{~V}$ when the discharge is fully developed. After the extinction of the electric energy input, $U_{\mathrm{br}}$ starts to increase again. The value of $U_{\mathrm{br}}$ recovers to $10 \mathrm{kV}$ within $10 \mu \mathrm{s}$. After that the recovery of $U_{\mathrm{br}}$ becomes slower, and $\mathrm{U}_{\mathrm{br}}$ recovers to $17 \mathrm{kV}$ at $200 \mu \mathrm{s}$. The slower rate of rise of $U_{\mathrm{br}}$ corresponds to the more flat temperature decay in the radial direction, and no significant increase of $U_{\mathrm{br}}$ is expected after $200 \mu \mathrm{s}$.

\subsection{Effects of parameters}

The temperature decay inside the spark channel strongly depends on the thermal conductivity $k$ of the gas. The impact of $k$ on the simulation results is inspected here. Figure 20 gives the $k$ of $\mathrm{N}_{2}$ calculated with equations $16(a)$ and $16(b)$ in the temperature region of $300-25000 \mathrm{~K}$. The value of the thermal conductivity calculated from the two equations differs when $T_{\mathrm{g}}>2000 \mathrm{~K}$, and the largest disparity happens at temperatures around $7000 \mathrm{~K}$ and $15000 \mathrm{~K}$. The modeled gas temperatures 


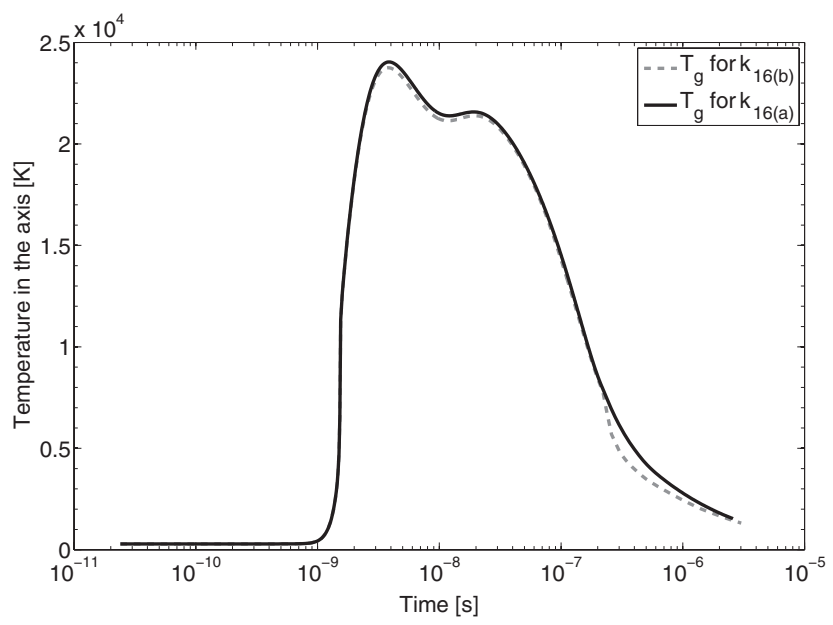

Figure 21. Modeled $\mathrm{N}_{2}$ temperature in the axis of the spark channel with thermal conductivity $k_{16(a)}$ and $k_{16(b)}$ respectively. The initial parameters are taken from section 3.4.

on the axis of the spark channel obtained with the two different thermal conductivities are given in figure 21 . The figure shows that temperature is not very sensitive to the choice of thermal conductivity model.

\section{Conclusions}

In this work the dielectric breakdown and recovery of the switch under a repetitive voltage source are investigated experimentally. The electric field across the gap is estimated from the measured spark current. A numerical model for the simulation of the discharge inside $\mathrm{SC} \mathrm{N}_{2}$ covering the streamerto-spark transition and discharge \& post-discharge stages is developed. The results of the modeling show that the gas temperature in the spark channel increases from background temperature to $5000 \mathrm{~K}$ within $1.5 \mathrm{~ns}$ after the streamer bridges the gap, and in the meanwhile the dielectric strength of the SC $\mathrm{N}_{2}$ drops to about $300 \mathrm{~V}$. During spark development the temperature rises to the peak value of $22000 \mathrm{~K}$ at $3 \mathrm{~ns}$ after the start of the spark formation. The spark formation time is much smaller than that in atmospheric pressure, although with a comparable reduced electric field. Due to the high heat transfer capability of the SCF, the $\mathrm{N}_{2}$ temperature on the spark axis decays to $1500 \mathrm{~K}$ at about $10 \mu \mathrm{s}$ after the breakdown. After $70 \mu$ s the dielectric strength of the gap recovers to about half of the cold breakdown value, and the recovery of the dielectric strength slows down afterwards because of slower temperature decay. The turbulence mechanism might be responsible for the slower temperature decay in the late stage. In the near future the dielectric recovery process of the SCF will be investigated by adding the turbulent relaxation mechanism on a time scale of $t_{\mathrm{d}} \geqslant 40 \mu \mathrm{s}$ up to the full recovery. The influence of the thermal conductivity on the simulation results is investigated. Different settings of thermal conductivity result in distinct temperature profiles along the time axis, but the differences are very small. Both experimental and numerical investigations indicate that SCF is an environmentally harmless insulating medium with proven high breakdown voltage and fast recovery speed. In order to work towards the utilization of SCF in real
CBs, performance of arc interruption followed by fast recovery voltage withstanding capability should be the next research approach.

\section{Acknowledgments}

This research is supported by the Dutch Technology Foundation STW, which is part of the Netherlands Organization for Scientific Research (NWO), and which is partly funded by the Ministry of Economic Affairs. Within this context it is also supported by the companies AnteaGroup, DNV-GL, ABB and SIEMENS. It is a pleasure to acknowledge the helpful discussions with T Christen, A Bourdon, M J Kushner, W Hundsdorfer, S Pancheshnyi, S Dujko.

\section{Appendix}

We use a zero-dimensional modeling platform ZDPlasKin [85] to model the dynamics of species in a streamer channel. The description of dynamics is given by the following equation:

$$
\frac{\mathrm{d}\left[n_{i}\right]}{\mathrm{d} t}=S_{i}
$$

where the source term $S_{i}$ represents the total rate of production and destruction of species $i$ in various processes. We use $\mathrm{N}_{2}$ kinetics from $[56,85]$ which includes the following species and states: e, $\mathrm{N}, \mathrm{N}_{2}, \mathrm{~N}^{+}, \mathrm{N}_{2}^{+}, \mathrm{N}_{3}^{+}, \mathrm{N}_{4}^{+}, \mathrm{N}_{2}\left(A^{3} \Sigma_{\mathrm{u}}^{+}, B^{3} \Pi_{\mathrm{g}}, C^{3} \Pi_{\mathrm{u}}\right.$, $\left.a^{\prime 1} \Sigma_{\mathrm{u}}^{-}\right), \mathrm{N}_{2}\left(X^{1}, v=1-8\right)$. The rate constants for electronneutral interactions are calculated using BOLSIG+ solver [55].

For self-consistent coupling between the electric field and the equation (A.1) we use the approach proposed in [86], where the electric field obeys the equation

$$
\frac{\mathrm{d} E}{\mathrm{~d} t}=\frac{\varepsilon_{0}}{e} \mu(|E|) E n_{\mathrm{e}} .
$$

Essentially we apply the same initial conditions as in [86], but scaled up to 80 bar. The maximum electric field is assumed to be $150 \mathrm{kV} \mathrm{cm}^{-1}$ at STP, which scales to $E(0)=12 \mathrm{MV} \mathrm{cm}^{-1}$ at 80 bar according to the similarity laws. Maximum electric field $E(0)$ corresponds to the initial electron density from the table 1 and reads as $n_{\mathrm{e}}(0)=n_{\mathrm{e}, 0}=8.87 \times 10^{20} \mathrm{~m}^{-3}$. The equations (A.1) and (A.2) are integrated together to obtain a decay of the electric field consistent with the conductivity. The integration is continued up to the electric field, which reaches the value of $0.4 \mathrm{MV} \mathrm{cm}^{-1}$. Afterwards, we continue integration with a constant electric field of $0.4 \mathrm{MV} \mathrm{cm}^{-1}$ until the end of the pulse (total pulse duration is taken to be equal to $100 \mathrm{~ns}$ ), and then in a vanishing field.

The results of the ZDPlasKin run are imported and analyzed in an open source software package PumpKin [57], which is freely available at www.pumpkin-tool.org. PumpKin automates the process of finding all principal pathways, i.e. the dominant reaction sequences, in a chemical reaction system. We run PumpKin for the time interval of $[0.01,1] \mathrm{ns}$ and for the species of interest of electron. The result of the analysis shows that the dominant electron loss mechanism is electronion dissociative recombination given by equation

$$
\mathrm{e}+\mathrm{N}_{4}^{+} \rightarrow \mathrm{N}_{2}+\mathrm{N}_{2} \text {. }
$$


According to PumpKin, this reaction is responsible for the $100 \%$ destruction of electron with a rate of $1.4 \times 10^{22} \mathrm{~cm}^{-3} \mathrm{~s}^{-1}$. On the other hand, the electron impact ionization

$$
\mathrm{e}+\mathrm{N}_{2} \rightarrow \mathrm{N}_{2}^{+}+2 \mathrm{e}
$$

is responsible for $98 \%$ of the production of electrons with a rate of $2.0 \times 10^{15} \mathrm{~cm}^{-3} \mathrm{~s}^{-1}$.

This is the reasoning behind why we, under the assumption that the reaction rates of nitrogen at standard temperature and pressure are applicable at 80 bar pressure, consider a kinetic equation in the form of (6).

\section{References}

[1] Boggs S A 1989 Sulphur hexafluoride: introduction to the material and dielectric IEEE Electr. Insul. Mag. 5 18-21

[2] Malik N H, Al-Arainy A A and Qureshi M I 1997 Electrical Insulation in Power Systems (New York: Marcel Dekker) pp 83-109

[3] Stoller P C, Seeger M, Iordanidis A A and Naidis G V 2013 $\mathrm{CO}_{2}$ as an arc interruption medium in gas circuit breakers IEEE Trans. Plasma Sci. 412359

[4] Lee A and Frost L S 1980 Interruption capability of gases and gas mixtures in a puffer-type interrupter IEEE Trans. Plasma Sci. 8362

[5] Noeske H O 1981 Arc thermal recovery speed in different gases and gas mixtures IEEE Trans. Power Apparatus Syst. PAS-100 4612-20

[6] Mochizuki K, Ueno T, Mizoguchi H, Yanabu S, Yuasa S and Okabe S 2004 Evaluation of interruption capability on various gases Gaseous Dielectrics X (New York: Springer) pp 265-70

[7] Uchii T, Hoshina Y, Mori T, Kawano H, Nakamoto T and Mizoguchi H 2004 Investigations on $\mathrm{SF}_{6}$-free gas circuit breaker adopting $\mathrm{CO}_{2}$ gas as an alternative arc-quenching and insulating medium Gaseous Dielectrics X (New York: Springer) pp 205-10

[8] Machida H, Takesue M and Smith R L Jr 2011 Green chemical processes with supercritical fluids: properties, materials, separations and energy J. Supercritical Fluids 60 2-15

[9] Takade M, Kiyan T, Miyaji K, Namihira T, Hara M and Akiyama H 2009 Plasma production in pressurized carbon dioxide up to supercritical conditions J. Plasma Fusion Res. SERIES 81326

[10] Lemmon E W, Jacobsen R T, Penoncello S G and Friend D G 2000 Thermodynamic properties of air and mixtures of nitrogen, argon, and oxygen from 60 to $2000 \mathrm{~K}$ at pressures to 2000 MPa J. Phys. Chem. Ref. Data 29331

[11] Breedveld G J F and Prausnitz J M 1973 Thermodynamic properties of supercritical fluids and their mixtures at very high pressures AIChE J. 19 783-96

[12] Zhang J, van Heesch E J M, Pemen A J M, Beckers F J C M, van Iersel A W M and van Driel S 2012 Breakdown voltage and recovery rate estimation of a supercritical nitrogen plasma switch Proc. 4th Euro-Asian Pulsed Power Conf. and 19th Int. Conf. on High-Power Particle Beams (EAPPC/BEAMS2012) (Karlsruhe, Germany, 30 September-4 October 2012)

[13] Horii K, Kosaki M, Pearmain A J and McNerney A J 1983 Correlation of electrical breakdown of supercritical helium in short gaps with partial discharge in cable samples Cryogenics 23102

[14] Nakayama K and Tanaka M 2012 Simulation analysis of triboplasma generation using the particle-in-cell/Monte Carlo collision (PIC/MCC) method J. Phys. D: Appl. Phys. 455203
[15] Nakayama S and Ito D 1986 Dc breakdown voltage characteristics in supercritical helium: breakdown in nonuniform fields Cryogenics 26 12-18

[16] Kiyan T, Takade M, Namihira T, Hara M, Sasaki M, Goto M and Akiyama H 2008 Polarity effect in dc breakdown voltage characteristics of pressurized carbon dioxide up to supercritical conditions IEEE Trans. Plasma Sci. 36821

[17] Babaeva N Y and Naidis G V 1996 Two-dimensional modelling of positive streamer dynamics in non-uniform electric fields in air J. Phys. D: Appl. Phys. 292423

[18] Sun A B, Teunissen J and Ebert U 2013 Why isolated streamer discharges hardly exist above the breakdown field in atmospheric air Geophys. Res. Lett. 40 2417-22

[19] Riousset J A, Pasko V P and Bourdon A 2010 Air-density-dependent model for analysis of air heating associated with streamers, leaders, and transient luminous events J. Geophys. Res. 115 A12321

[20] Naidis G V 1999 Simulation of streamer-to-spark transition in short non-uniform air gaps J. Phys. D: Appl. Phys. 322649

[21] Aleksandrov N L, Bazelyan E M, Dyatko N A and Kochetov I V 1998 Streamer breakdown of long air gaps Plasma Phys. Rep. 24541

[22] Mnatsakanyan A Kh and Naidis G V 1986 The vibrational-energy balance in a discharge in air High Temp. 23 (Engl. transl.)

[23] Aleksandrov N L, Bazelyan E M, Kochetov I V and Dyatko N A 1997 The ionization kinetics and electric field in the leader channel in long air gaps J. Phys. D: Appl. Phys. 301616

[24] Naidis G V 2005 Dynamics of streamer breakdown of short non-uniform air gaps J. Phys. D: Appl. Phys. 383889

[25] Marode E 1983 The Glow-to-Arc Transition (NATO Advanced Science Institutes (ASI) Series B vol 93) p 119

[26] Eichwald O, Yousfi M, Bayle P and Jugroot M 1998 Modeling and three-dimensional simulation of the neutral dynamics in an air discharge confined in a microcavity: I. Formation and free expansion of the pressure waves J. Appl. Phys. 844704

[27] Eichwald O, Bayle P, Yousfi Y and Jugroot M 1998 Modeling and three dimensional simulation of the neutral dynamics in an air discharge confined in a microcavity: II. Analysis of the wall and geometry effects J. Appl. Phys. 844716

[28] Plooster M N 1971 Numerical simulation of spark discharges in air Phys. Fluids 142111

[29] Akram M and Lundgren E 1996 The evolution of spark discharges in gases: I. Macroscopic models J. Phys. D: Appl. Phys. 292129

[30] Akram M 1996 The evolution of spark discharges in gases: II Numerical solution of one-dimensional models J. Phys. D: Appl. Phys. 292137

[31] Brode H L 1955 Numerical solutions of spherical blast waves J. Appl. Phys. 26 766-75

[32] Yan K, van Heesch E J M, Pemen A J M, Huijbrechts P A H J and van der Laan P C T 2001 A $10 \mathrm{~kW}$ high-voltage pulse generator for corona plasma generation Rev. Sci. Instrum. 72 2443-7

[33] Cookson A H 1970 Electrical breakdown for uniform fields in compressed gases Proc. IEE 117 269-80

[34] Haidara M, Denat A and Atten P 1997 Corona discharges in high pressure air J. Electrostat. 40-41 61-6

[35] Watson P K and Sharbaugh A H 1969 The electric strength of nitrogen at elevated pressures and small gap spacings $J$. Appl. Phys. 40 328-34

[36] Kiyan T, Uemura A, Roy B C, Namihira T, Hara M, Sasaki M, Goto M and Akiyama H 2007 Negative dc prebreakdown phenomena and breakdown-voltage characteristics of pressurized carbon dioxide up to supercritical conditions IEEE Trans. Plasma Sci. 635 656-62

[37] Sawada M, Tomai T, Ito T, Fujiwara H and Terashima K 2006 Micrometer-scale discharge in high-pressure $\mathrm{H}_{2} \mathrm{O}$ and $\mathrm{Xe}$ 
environments including supercritical fluid J. Appl. Phys. 100123304

[38] Akiyama H, Tanigawa T, Maeda S, Takaki K and Kristiansen M 1991 Voltage-current characteristics of high-current pulsed discharges in SCF Electr. Eng. Japan $11129-36$

[39] Naidis G V 2009 Positive and negative streamers in air: velocity-diameter relation Phys. Rev. E 79057401

[40] Babaeva N Y and Naidis G V 1997 Dynamics of positive and negative streamers in air in weak uniform electric fields IEEE Trans. Plasma Sci. 25375

[41] Montijn C, Hundsdorfer W and Ebert U 2006 An adaptive grid refinement strategy for the simulation of negative streamers J. Comput. Phys. 219801

[42] Popov N A 2003 Formation and development of a leader channel in air Plasma Phys. Rep. 29695

[43] Popov N A 2009 Study of the formation and propagation of a leader channel in air Plasma Phys. Rep. 35785

[44] Montijn C and Ebert U 2006 Diffusion correction to the Raether-Meek criterion for the avalanche-to-streamer transition J. Phys. D: Appl. Phys. 39 2979-92

[45] Luque A and Ebert U 2012 Density models for streamer discharges: beyond cylindrical symmetry and homogeneous media J. Comput. Phys. 231904

[46] Nijdam S, van de Wetering F M J H, Blanc R, van Veldhuizen E M and Ebert U 2010 Probing photo-ionization: experiments on positive streamers in pure gases and mixtures J. Phys. D: Appl. Phys. 43145204

[47] Luque A, Ratushnaya V and Ebert U 2008 Positive and negative streamers in ambient air: modelling evolution and velocities J. Phys. D: Appl. Phys. 41234005

[48] Li C, Ebert U and Brok W J M 2008 Avalanche-to-streamer transition in particle simulations IEEE Trans. Plasma Sci. 36910

[49] Naidis G V 2010 Modelling of streamer propagation in atmospheric-pressure helium plasma jets J. Phys. D: Appl. Phys. $\mathbf{4 3} 2001$

[50] Pasko V 2006 Theoretical modeling of sprites and jets Sprites, Elves and Intense Lightning Discharges (NATO Science Series II: Mathematics, Physics and Chemistry vol 225) ed M Füllekrug et al (Berlin: Springer) pp 253-311

[51] Ebert U, Nijdam S, Li C, Luque A, Briels T and van Veldhuizen E 2010 Review of recent results on streamer discharges, discussion of their relevance for sprites and lightning J. Geophys. Res. 115 DOI:10.1029/2009JA014867

[52] Korolev Yu D, Bykov N M and Ivanov S N 2008 Subnanosecond processes in the stage of breakdown formation in gas at a high pressure Plasma Phys. Rep. 34 1022-7

[53] Dujko S, Markosyan A H, White R D and Ebert U 2013 High-order fluid model for streamer discharges: I. Derivation of model and transport data J. Phys. D: Appl. Phys. 465202

[54] Kossyi I A, Kostinsky A Y, Matveyev A A and Silakov V P 1992 Kinetic scheme of the non-equilibrium discharge in nitrogen-oxygen mixtures Plasma Sources Sci. Technol. 1207

[55] Hagelaar G J M and Pitchford L C 2005 Solving the Boltzmann equation to obtain electron transport coefficients and rate coefficients for fluid models Plasma Sources Sci. Technol. 14722

[56] Flitti A and Pancheshnyi S 2009 Gas heating in fast pulsed discharges in $\mathrm{N}_{2}-\mathrm{O}_{2}$ mixtures Eur. Phys. J. Appl. Phys. 45021001

[57] Markosyan A H, Luque A, Gordillo-Váazquez F J and Ebert U 2014 PumpKin: a tool to find principal pathways in plasma chemical models Comput. Phys. Commun. 185 2697-702

[58] Babaeva N Yu and Naidis G V 2001 On streamer dynamics in dense media J. Electrostat. 53 123-33
[59] Achat S, Teisseyre Y and Marode E 1992 The scaling of the streamer-to-arc transition in a positive point-to-plane gap with pressure J. Phys. D: Appl. Phys. 25661

[60] Popov N A 2001 Investigation of the mechanism for rapid heating of nitrogen and air in gas discharges Plasma Phys. Rep. 27886

[61] Popov N A 2011 Fast gas heating in a nitrogen-oxygen discharge plasma: I. Kinetic mechanism J. Phys. D: Appl. Phys. 44 B5201

[62] Popov N A 2013 Dissociation of nitrogen in a pulse-periodic dielectric barrier discharge at atmospheric pressure Plasma Phys. Rep. 39 420-4

[63] Sebacher D I 1967 A correlation of $\mathrm{N}_{2}$ vibrational goes to translational relaxation times AIAA J. 5819

[64] Sebacher D I and Guy R W 1974 Vibrational relaxation in expanding $\mathrm{N}_{2}$ and air Technical Report NASA

[65] Naidis G V 2007 Simulation of convection-stabilized low-current glow and arc discharges in atmospheric-pressure air Plasma Sources Sci. Technol. 16297

[66] Chatelet M and Chesnoy J 1985 New results on the vibrational relaxation time in compressed nitrogen at $293 \mathrm{~K}$ Chem. Phys. Lett. 122 550-2

[67] Seeger M, Niemeyer L, Christen T, Schwinne M and Dommerque R 2006 An integral arc model for ablation controlled arcs based on CFD simulations J. Phys. D: Appl. Phys. 392180

[68] Stephan K, Krauss R and Laesecke A 1987 Viscosity and thermal conductivity of nitrogen for a wide range of fluid states J. Phys. Chem. Ref. Data 16993

[69] Plooster M N 1970 Shock waves from line sources. Numerical solutions and experimental measurements Phys. Fluids 132665

[70] Taylor G 1950 The formation of a blast wave by a very intense Explosion: II. The atomic explosion of 1945 Proc. R. Soc. Lond. A 201 175-86

[71] Lin S-C 1954 Cylindrical shock waves produced by instantaneous energy release J. Appl. Phys. 25 54-7

[72] Vonneumann J and Richtmyer R D 1950 J. Appl. Phys. 21232

[73] Press W H 2007 Numerical Recipes (The Art of Scientific Computing) 3rd edn (Cambridge: Cambridge University Press)

[74] Wormeester G, Pancheshnyi S, Luque A, Nijdam S and Ebert U 2010 Probing photo-ionization: simulations of positive streamers in varying $\mathrm{N}_{2}: \mathrm{O}_{2}$ mixtures $J$. Phys. $D$ : Appl. Phys. 43505201

[75] Nijdam S, van de Wetering F M J H, Blanc R, van Veldhuizen E M and Ebert U 2010 Probing photo-ionization: experiments on positive streamers in pure gases and mixtures J. Phys. D: Appl. Phys. 43145204

[76] Webster J (ed) 1999 Conduction and breakdown in gases Wiley Encyclopedia of Electrical and Electronics Engineering (New York: Wiley) pp 141-2

[77] Liu Z, van Veldhuizen E M, van Heesch E J M and Pemen A J M 2011 Strong density gradients in postdischarges in argon and air IEEE Trans. Plasma Sci. 39 2092-3

[78] Borghese A, D’Alessio A, Diana M and Venitozzi C 1989 Development of hot nitrogen kernel, produced by a very fast spark discharge Symp. (Int.) Combust. 22 1651-9

[79] Shneider M N 2006 Turbulent decay of after-spark channels Phys. Plasmas 13073501

[80] Smith R K and Hughes J P 2010 Ionization equilibrium timescales in collisional plasmas Astrophys. J. 718583

[81] Lino da Silva M, Guerra1 V and Loureiro J 2009 A review of non-equilibrium dissociation rates, models for atmospheric entry studies Plasma Sources Sci. Technol. 18034023

[82] Niemeyer L 1995 A generalized approach to partial discharge modeling IEEE Trans. Dielectr. Electr. Insul. 2 510-28 
[83] Seeger M, Naidis G, Steffens A, Nordborg H and Claessens M 2005 Investigation of the dielectric recovery in synthetic air in a high voltage circuit breaker J. Phys. D: Appl. Phys. 381795

[84] Malik N H 1981 Streamer breakdown criterion for compressed gases IEEE Trans. Electr. Insul. EI-16 463-7

[85] Pancheshnyi S, Eismann B, Hagelaar G and Pitchford L 2008 Computer code ZDPlasKin University of Toulouse,
LAPLACE, CNRS-UPS-INP, Toulouse, France, www.zdplaskin.laplace.univ-tlse.fr

[86] Nijdam S, Takahashi E, Markosyan A H and Ebert U 2014 Investigation of positive streamers by double-pulse experiments, effects of repetition rate and gas mixture Plasma Sources Sci. Technol. 23025008 